University of Nebraska - Lincoln

DigitalCommons@University of Nebraska - Lincoln

Daugherty Water for Food Global Institute:

Faculty Publications

Daugherty Water for Food Global Institute

2021

\title{
Nanomaterials in the environment, human exposure pathway, and health effects: A review
}

Arindam Malakar

Sushil R. Kanel

Chittaranjan Ray

Daniel D. Snow

Mallikarjuna N. Nadagouda

Follow this and additional works at: https://digitalcommons.unl.edu/wffdocs

Part of the Environmental Health and Protection Commons, Environmental Monitoring Commons, Hydraulic Engineering Commons, Hydrology Commons, Natural Resource Economics Commons, Natural Resources and Conservation Commons, Natural Resources Management and Policy Commons, Sustainability Commons, and the Water Resource Management Commons

This Article is brought to you for free and open access by the Daugherty Water for Food Global Institute at DigitalCommons@University of Nebraska - Lincoln. It has been accepted for inclusion in Daugherty Water for Food Global Institute: Faculty Publications by an authorized administrator of DigitalCommons@University of Nebraska Lincoln. 


\title{
Nanomaterials in the environment, human exposure pathway, and health effects: A review
}

\author{
Arindam Malakar, ${ }^{1}$ Sushil R. Kanel, ${ }^{1,2}$ Chittaranjan Ray, ${ }^{1}$ \\ Daniel D. Snow, ${ }^{3} \&$ Mallikarjuna N. Nadagouda ${ }^{4}$
}

1 Nebraska Water Center, part of the Robert B. Daugherty Water for Food Global Institute 2021 Transformation Drive, University of Nebraska, Lincoln, NE 68588-0844, USA

2 Department of Chemistry, Wright State University, Dayton, OH 45435, USA

3 School of Natural Resources and Nebraska Water Center, part of the Robert B. Daugherty Water for Food Global Institute, 202 Water Sciences Laboratory, University of Nebraska, Lincoln, NE 68583-0844, USA

4 Department of Mechanical and Materials Engineering, Wright State University, 3640 Colonel Glenn Hwy., Dayton, OH 45435, USA

Corresponding author - S.R. Kanel, Nebraska Water Center, part of the Robert B. Daugherty Water for Food Global Institute 2021 Transformation Drive, University of Nebraska,

Lincoln, NE 68588-0844, USA; email sushil.kanel@wright.edu

\section{Highlights}

- The ubiquitous presence of natural and synthetic nanomaterials in the environment

- Nanomaterials influence on the natural ecosystem.

- Exposure pathways and life cycle of nanomaterials in the human body

- Nanotoxicity of nanomaterials on human health

Published in Science of the Total Environment 759 (2021) 143470

doi:10.1016/j.scitotenv.2020.143470

Copyright (C) 2020 Elsevier B.V. Useed by permission.

Submitted 20 August 2020; revised 24 October 2020; accepted 24 October 2020; published

17 November 2020. 


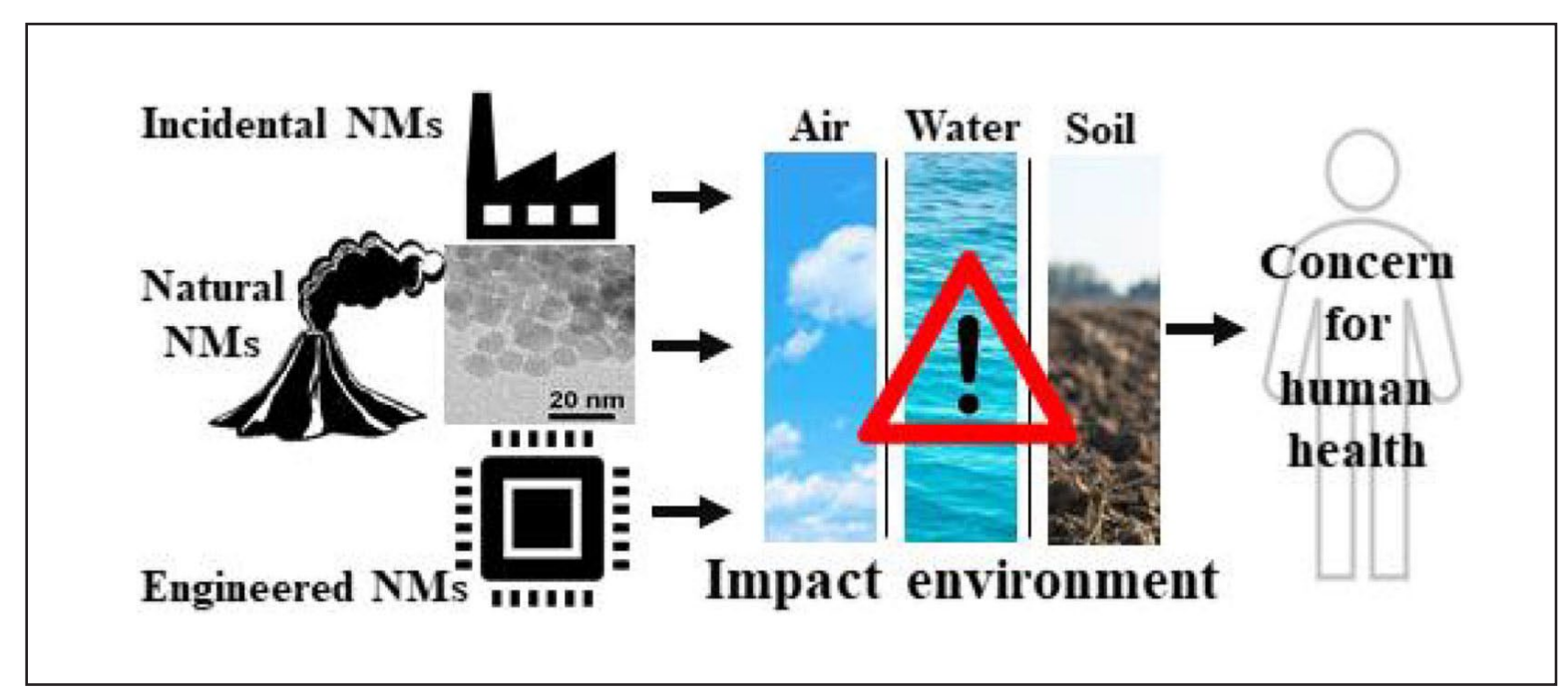

\title{
Graphical abstract
}

\begin{abstract}
Nanomaterials (NMs), both natural and synthetic, are produced, transformed, and exported into our environment daily. Natural NMs annual flux to the environment is around $97 \%$ of the total and is significantly higher than synthetic NMs. However, synthetic NMs are considered to have a detrimental effect on the environment. The extensive usage of synthetic NMs in different fields, including chemical, engineering, electronics, and medicine, makes them susceptible to be discharged into the atmosphere, various water sources, soil, and landfill waste. As ever-larger quantities of NMs end up in our environment and start interacting with the biota, it is crucial to understand their behavior under various environmental conditions, their exposure pathway, and their health effects on human beings. This review paper comprises a large portion of the latest research on NMs and the environment. The article describes the natural and synthetic NMs, covering both incidental and engineered NMs and their behavior in the natural environment. The review includes a brief discussion on sampling strategies and various analytical tools to study NMs in complex environmental matrices. The interaction of NMs in natural environments and their pathway to human exposure has been summarized. The potential of NMs to impact human health has been elaborated. The nanotoxicological effect of NMs based on their inherent properties concerning to human health is also reviewed. The knowledge gaps and future research needs on NMs are reported. The findings in this paper will be a resource for researchers working on NMs all over the world to understand better the challenges associated with NMs in the natural environment and their human health effects.
\end{abstract}

Keywords: Nanomaterials, Environmental impact, Human exposure, Health effects 


\section{Contents}

1. Introduction. . . . . . . . . . . . . . . . . . . . . . 3

2. Nanomaterials. . . . . . . . . . . . . . . . . . . . . . . . . 6

2.1. Natural nanomaterials (NNMs) $\ldots \ldots . \ldots 6$

2.1.1. Organic NNMs . . . . . . . . . . . . . . . . . . . . . 8

2.1.2. NNMs from physical, abiotic, and biotic processes . . . . . . . . . . . 8

2.2. Synthetic nanomaterials . . . . . . . . . . . . . . . . . . . . . . . 9

2.2.1. Incidental NMs. . . . . . . . . . . . . . . . . . . . . . . . 10

2.2.2. Engineered nanomaterials . . . . . . . . . . . . . . . . . . . . 10

3. Nanomaterials in the environment . . . . . . . . . . . . . . . . . 15

3.1. Natural nanomaterials in the environment . . . . . . . . . . . . 16

3.2. Synthetic nanomaterials in the environment . . . . . . . . . . . . . . 19

4. Sampling and analysis of NMs in the environment . . . . . . . . . . . . 24

5. Nanomaterial exposure and human health concerns . . . . . . . . . . . 26

5.1. NMs human exposure pathways . . . . . . . . . . . . . . . . . . . . . . . . 28

5.2. Circulation and redistribution of NMs in the human body . . . . . . 30

5.3. NMs impact on human health . . . . . . . . . . . . . . . . . 31

6. Conclusions . . . . . . . . . . . . . . . . . . . . . . . . . . . . . . . 36

7. Future perspective $\ldots \ldots \ldots 36$

Competing interest. . . . . . . . . . . . . . . . . . . . . 37

Acknowledgments . . . . . . . . . . . . . . . . . . . . . . . . . . 37

References . . . . . . . . . . . . . . . . . . . . . . . . . 37

\section{Introduction}

Nanomaterials (NMs), both organic and inorganic, can be potential pollutants and have remained mostly unidentified due to the limitations of analytical techniques (Besseling et al., 2019; Ma et al., 2016; Malakar et al., 2019). NMs or nanoparticles (NPs) are defined based on their size; the sizes can vary up to $1000 \mathrm{~nm}$ though commonly defined as one dimension size between 1 and $100 \mathrm{~nm}$ (Jeevanandam et al., 2018). NMs are characterized by some specific properties such as surface area, surface charge, degree of agglomeration, particle morphology, and surface coating (Turan et al., 2019). However, it has been suggested that changes in fundamental properties from the bulk material should be the basis for the upper size limit (Banfield and Zhang, 2001). NMs can be synthesized artificially for commercial use, can be an unintentional by-product, or occur naturally. The biosphere is rich in anthropogenic nanosized particles and other natural NMs, though we have only recently become aware of their occurrence and importance (Hochella et al., 2019). NMs 
present in the natural environment can find their way to the human body and impact health as they interact with humans directly or indirectly.

Nanotechnology (technology that utilizes NMs) has potential applications in agriculture, engineering, manufacturing, and medicine. Recent research focuses on improving and making nanotechnology more viable. The nanotechnology market is estimated to be 55 billion US dollars by 2022 , and $70 \%$ of these growths will be in the electronics, energy, and biomedical sectors (Inshakova and Inshakov, 2017). Enhancement in the use of NMs has risen exponentially, which has increased NMs presence in different natural resources viz, air, water, and soil (Belal and ElRamady, 2016; González-Gálvez et al., 2017; Malakar and Snow, 2020; Sun et al., 2017). Increased NM use is also reflected in the amount of research regarding fate in the environment and the potential impact on health in the last decade. Further, natural or synthetic NMs can easily pass through $0.2 \mu \mathrm{m}$ filters and may not be accurately distinguished in aqueous sample analysis (Malakar and Snow, 2020).

This review article takes a unique approach to integrate studies on both natural and synthetic (incidental and engineered) NMs (Table 1) role in the environment, their analysis techniques, and the potential impact of NMs on human health, along with elaborating on the prevailing knowledge gaps. This review evaluates the cause and possible effects of the NMs occurrence in the natural environment. The article summarized different groups and subgroups of natural and synthetic NMs. The literature evaluated here is based on the search criteria consisting of keywords: nanomaterials, and environmental fate, and human, and the last five years publications were included (Fig. 1) to keep the content concise and timely. The search was further refined to environmental science and nanoscience nanotechnology, the two broader categories in the Web of Science citation index. The literature was separately summarized for human exposure potential and human health impact considering the exposure pathways such as air, water, and food, concerning agricultural produce accumulating NMs from soil or addition in packaged food. Other relevant articles were included based on the work of most prominent authors in the field studying the fate of NMs in the environment and human impact. This review will primarily emphasize the fate of NMs in different environmental compartments, followed by a brief discussion of various analytical tools utilized to understand NMs in these complex matrices. The probability of NMs acting as a vector for exposure to humans will be discussed. The impact of NMs on human health will 
Table 1. Summary of the presence of various natural and synthetic NMs in the natural environment.

\begin{tabular}{|c|c|c|}
\hline Nanomaterial type & Presence in the environment & References \\
\hline \multicolumn{3}{|l|}{ Natural nanomaterials } \\
\hline Silicon dioxide & $\begin{array}{l}\text { Atmosphere, surface and } \\
\text { groundwater }\end{array}$ & Lungu et al., 2015 \\
\hline Carbon nanotubes & Atmosphere, soot and fires & Griffin et al., 2018 \\
\hline Mercury nanoparticles & Soil and water resources & Ghoshdastidar and Ariya, 2019 \\
\hline Ferrihydrite & Soil, surface and groundwater & Malakar and Snow, 2020 \\
\hline Iron oxyhydroxide & Oceans and seas & Hochella et al., 2019 \\
\hline Manganese based NMs & Oceans and seas & Hochella et al., 2019 \\
\hline Sulfur NMs & Mineral wells, springs & Griffin et al., 2018 \\
\hline Silver nanomaterials & $\begin{array}{l}\text { Hydrothermal vents, surface } \\
\text { water, wastewater }\end{array}$ & Sharma and Zboril, 2017 \\
\hline Polymeric nanomaterials & Atmosphere & Courty and Martinez, 2015 \\
\hline $\begin{array}{l}\text { Nickel, zinc, cadmium, silver, } \\
\text { tin, selenium, lead bismuth }\end{array}$ & Volcanic eruptions, atmosphere & Ermolin et al., 2018 \\
\hline \multicolumn{3}{|l|}{ Synthetic nanomaterials } \\
\hline Platinum & Atmosphere & $\begin{array}{l}\text { Baalousha et al., 2016; } \\
\text { Bäuerlein et al., } 2017\end{array}$ \\
\hline Titanium dioxide & $\begin{array}{l}\text { Wastewater, surface runoff, } \\
\text { stormwater, surface and } \\
\text { groundwater, landfills, } \\
\text { atmosphere }\end{array}$ & $\begin{array}{l}\text { Baalousha et al., 2016; } \\
\text { Bäuerlein et al., 2017; } \\
\text { Peters et al., } 2018\end{array}$ \\
\hline Fullerenes $\left(\mathrm{C}_{60}\right)$ & Air; sludge; wastewater & Bäuerlein et al., 2017 \\
\hline Iron oxide & $\begin{array}{l}\text { Atmosphere, stormwater, } \\
\text { surface water; tap water }\end{array}$ & $\begin{array}{l}\text { Baalousha et al., 2016; } \\
\text { Malakar and Snow, 2020; } \\
\text { Westerhoff et al., } 2018\end{array}$ \\
\hline Cerium oxide & River water & Peters et al., 2018 \\
\hline Nanoplastics & Surface water, sea and ocean & Lehner et al., 2019 \\
\hline Zinc oxide & $\begin{array}{l}\text { Soil, surface water, crops, } \\
\text { landfills }\end{array}$ & $\begin{array}{l}\text { Bundschuh et al., 2018; } \\
\text { Durenkamp et al., 2016; } \\
\text { Sousa and Ribau Teixeira, } 2020\end{array}$ \\
\hline Zinc sulfide & Stormwater & Baalousha et al., 2016 \\
\hline Lead sulfide & Atmosphere & Baalousha et al., 2016 \\
\hline Carbon nanotubes & $\begin{array}{l}\text { Atmosphere, wastewater, } \\
\text { surface water, landfills }\end{array}$ & Sun et al., 2016 \\
\hline Silver nanomaterials & Wastewater, landfills, sludge & $\begin{array}{l}\text { Alizadeh et al., 2019; } \\
\text { Bundschuh et al., 2018; } \\
\text { Kunhikrishnan et al., 2015; } \\
\text { Sousa and Ribau Teixeira, 2020 }\end{array}$ \\
\hline
\end{tabular}




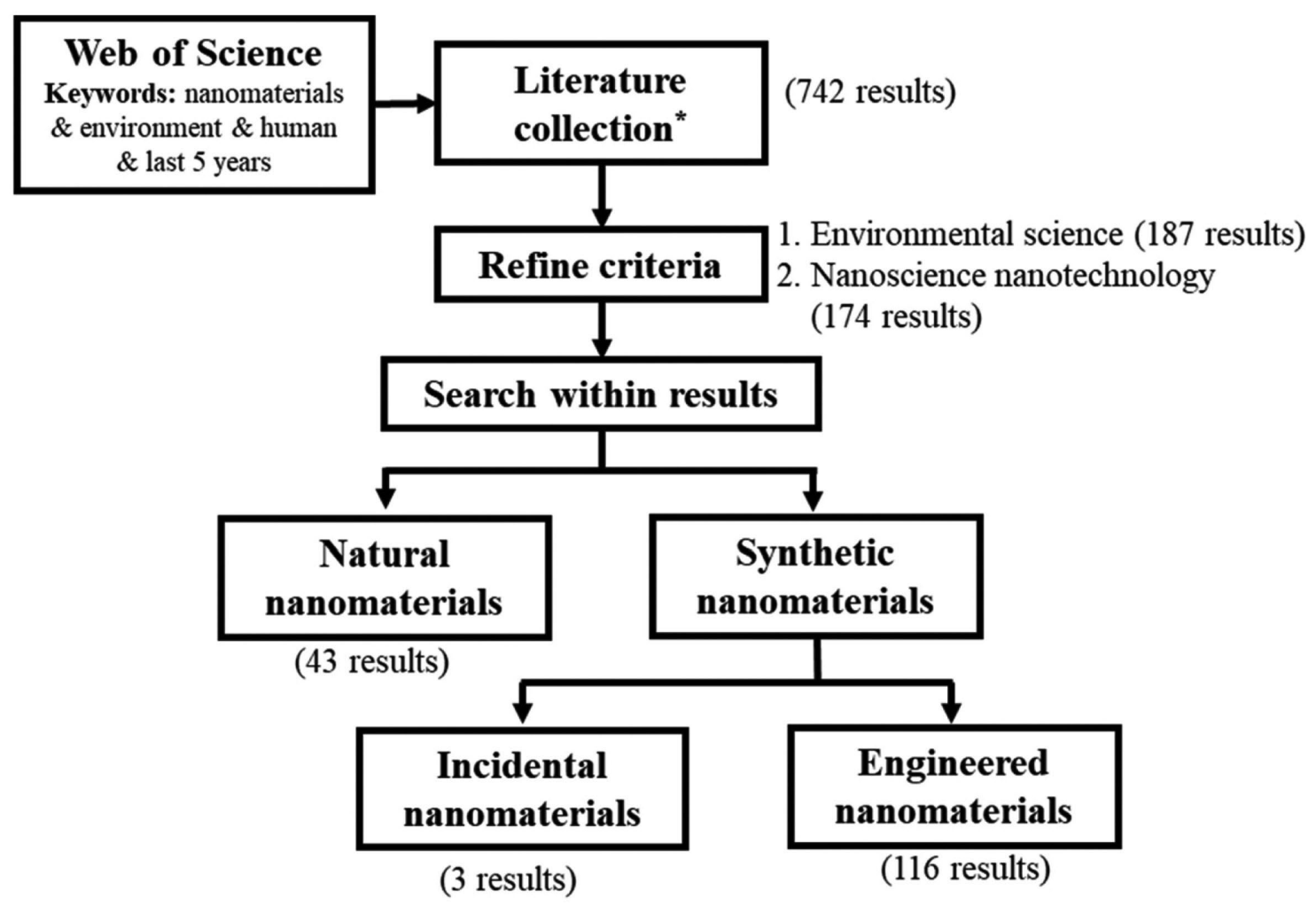

${ }^{*}$ Other relevant articles were also included outside the search window and time, which were based on the work of prominent authors in the field studying fate of nanomaterials in the environment and impact of human health

Fig. 1. Main search criteria for selection and categorization of NMs for the evaluation of publications for review.

be assessed in depth. The prevailing knowledge gaps will be addressed to consider future opportunities. From this review paper, readers from the scientific community will better understand the present knowledge of the fate and transport of NMs in various natural resources and the potential exposure and nanotoxicity in humans.

\section{Nanomaterials}

\subsection{Natural nanomaterials (NNMs)}

Naturally occurring nanomaterials in the Earth's crust is classified as Natural NMs (NNMs). These are generally formed through different 
biogeochemical processes, as shown in Fig. 2 under the natural nanomaterial section. A thousand megatons of NNMs of size range between one to thousand nanometers, cycle around the Earth each year (Hochella et al., 2019; Tabasum et al., 2019). It is estimated that around 342 megaton/yr is the flux of NNMs to Earth's atmosphere (Hochella et al., 2019), and these NNMs can also make their way to natural water sources (Neil et al., 2016). Current research is focused on understanding the role of NNMs in the environment and their contribution to different element

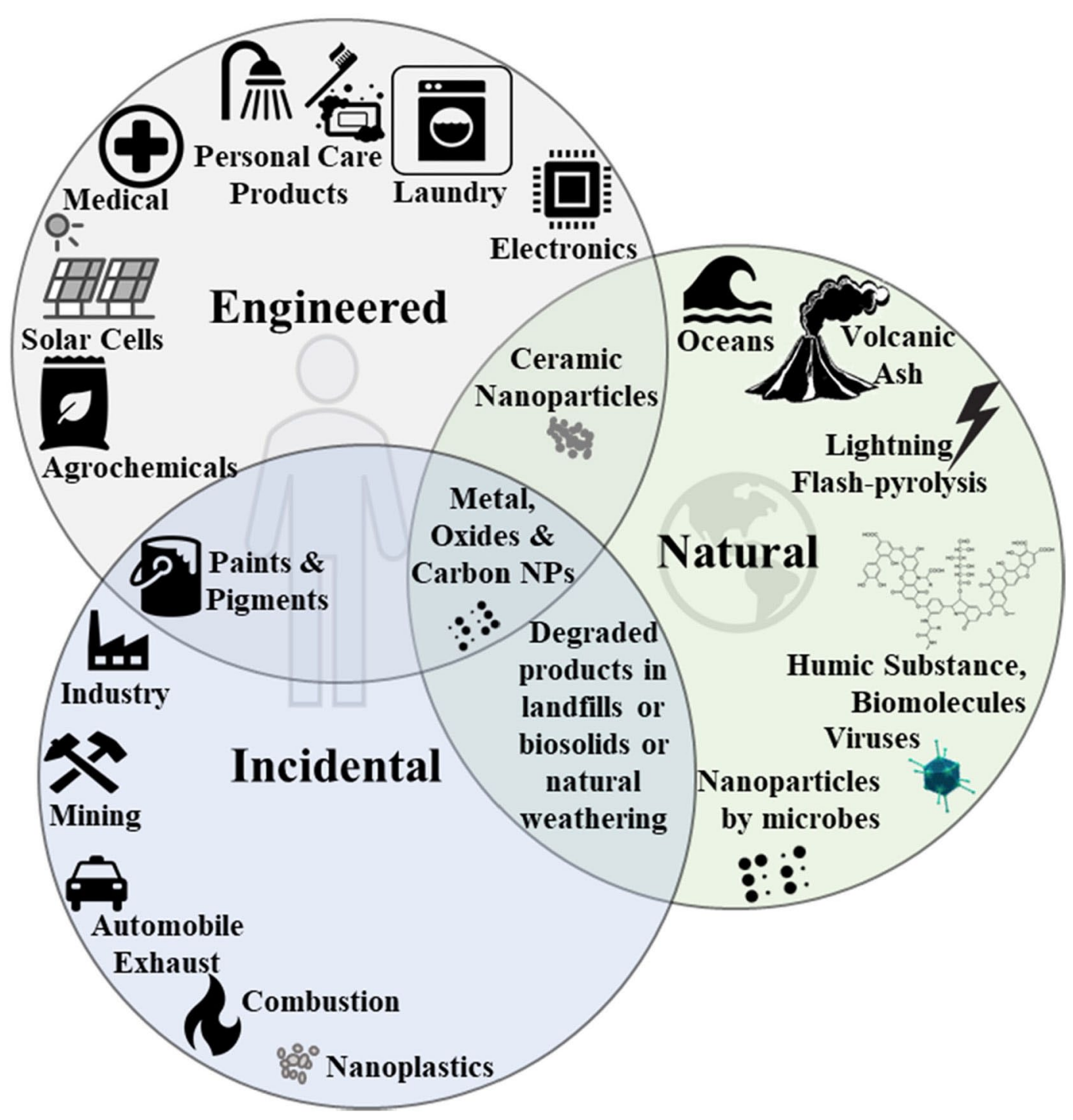

Fig. 2. Different classes of natural and anthropogenic nanomaterials. It shows how these various nanomaterials are formed, where they are primarily present, and where the engineered, natural and, incidental NMs are majorly utilized. 
cycles. NNMs are known to safeguard diverse ecosystems by enabling biogeochemical reactions (Hartland et al., 2013). NNMs widely vary in composition, covering organic and inorganic forms, and morphology (Griffin et al., 2018; Westerhoff et al., 2018). Natural chemical weathering processes, volcanic eruptions, aeroplasma, lightning, flash-pyrolysis, metal, and metal oxides nanomaterials formed by biotic or abiotic interactions (like minerals of sulfur, selenium, uranium) can all generate NNMs (Courty et al., 2020; Griffin et al., 2018; Malakar and Snow, 2020) (Fig. 2).

\subsubsection{Organic NNMs}

Humic substances are the chemically extracted fraction of the total environmental organic carbon pool and are considered the most abundant form of NNM. Humic substances can be a mixture of the aliphatic and aromatic organic compounds of high or low molecular weight with a size of fewer than five nanometers (Grillo et al., 2015). Peptides, peptidoglycans, proteins, and polysaccharides, along with viruses, are the biomolecules that can be of nanoscale size (Griffin et al., 2018; Westerhoff et al., 2018).

\subsubsection{NNMs from physical, abiotic, and biotic processes}

Active volcanos annually add tons of NNMs in the biosphere (Ermolin et al., 2018). NNMs from volcanos can travel long distances, the wind being their primary vector, and contain multiple elements such as nickel, zinc, cadmium, sulfur, and lead (Ermolin et al., 2018). The concentrations of these metal and metalloids in volcanic ash NNMs can range anywhere between 10 and 500 times higher than the background (Ermolin et al., 2018). However, the compositions and purity of NNMs forming through volcanic ash are generally mixed due to their natural origin (Faulstich et al., 2017). Temperature, high-speed physical collisions, shock waves, radiation, and pressure, can produce NMs in the space (Jeevanandam et al., 2018). Studies show how gas and solid aerosols, as seized in the Mach cone of a bolide while penetrating the Earth atmosphere, are transformed into a new range of polymeric nanomaterials (Courty and Martinez, 2015). Flash-pyrolysis associated with lightning is also known to form NMs (Courty et al., 2020), and lightning strikes directly on soils can also produce NMs.

One subtle, but the key point in considering NM occurrence is the difference between natural nanominerals and mineral nanomaterials. 
Minerals which only exist in the nanoscale size range are known as nanominerals such as ferrihydrite or clay particles (Malakar and Snow, 2020). Nanosized minerals, which are known to exist in bulk size, are defined as mineral nanomaterials. The natural aquatic environment can comprise of multiple forms of nano- and microscopic polydisperse minerals mainly from calcium, and sometimes iron oxides (Griffin et al., 2018; Westerhoff et al., 2018). Organic and inorganic NNMs are also known to co-exist, where metal and metal oxide NMs are bound to organic NNMs such as humic acid. These combination of metalorganic NNMs are prevalent in the Earth's surface and plays a crucial role in controlling different biogeochemical cycles (Liu et al., 2018; Zhang et al., 2018).

Biotic processes such as microbial respiration by algae, bacteria, and fungi can produce NNMs of fixed stoichiometry and high monodispersity (Hochella et al., 2015; Srivastava et al., 2015). Inorganic natural NMs of copper, iron, gold, selenium, silver, uranium can form via microbial respiration (Das et al., 2017; Joshi et al., 2018), and organic NMs such as humic matter, can be a product of microbial degradation. Inorganic natural NMs of calcium, selenium, iron, and silicon can also be produced by biomineralization and are highly monodispersed (Jain et al., 2017). These inorganic NNMs can be induced by microbes and be produced as a by-product or can be an inherent part of various microbial processes (Sharma et al., 2015).

\subsection{Synthetic nanomaterials}

Anthropogenic activities, both intentional and unintentional, can produce nanoscale materials defined as synthetic NMs. However, the annual flux of synthetic NMs into the environment is significantly less than natural NM and is estimated to be around 10.3 megatons/yr to the atmosphere (Hochella et al., 2019). Even though the synthetic NMs are small volume compared to NNMs, these NMs are considered a threat to the environment and are termed as pollutants (Bundschuh et al., 2018; Malakar and Snow, 2020). Broadly, synthetic NMs are classified as incidental NMs (INMs) and engineered NMs (ENMs) (Fig. 2). Recent reports provided a summary of synthetic NMs (common and emerging) that are likely to be released in the urban environment from various sources (Baalousha et al., 2016; Xu et al., 2020). 


\subsubsection{Incidental NMs}

Anthropogenic activities leading to the unintentional formation of nanomaterials are termed as incidental nanomaterials (Baalousha et al., 2016). Fig. 2 shows different sources of incidental nanomaterials, which comprise automobile exhaust, industrial waste, mining waste, combustion processes, wear, and corrosion processes. Incidental nanomaterials can be carbon-based such as carbon soot from combustion, nanoplastics from plastic degradation, or metal-based, generated from corrosion in tap water, and can potentially be exposed to humans (Kunhikrishnan et al., 2015; Lehner et al., 2019; Maher et al., 2016; Venkatesan et al., 2018; Westerhoff et al., 2018). Fig. 3, reproduced from Baalousha et al. (2016), shows a case study for incidental NMs, where $\mathrm{PM}_{2.5}$ samples of air were collected in Shanghai, China, on a hazy day, and were characterized by transmission electron microscopy (TEM) and X-ray energy dispersive spectroscopy (X-EDS). Bright-field TEM micrograph (a) and X-EDS maps (b-i) shows the presence of incidental NMs of aluminum, iron, and lead, indicating the presence of iron oxide ( $c$ and $h$ ), galena ( $f$ and $i$ ), and calcium silicate (c, e, and g) NMs (Baalousha et al., 2016). INMs are closer to NNMs concerning stoichiometry and morphology, as these two aspects of INMs are not well-defined.

\subsubsection{Engineered nanomaterials}

Nanomaterials that are produced for commercial usage are defined as engineered nanomaterials (Baun et al., 2017; Singh, 2016). ENMs usage is widespread, covering the energy sector, telecommunication sector, computing, agrichemicals, and personal care products. ENMs usage is increasing day by day, and more ENMs are making their way to various water sources (Malakar et al., 2019; Malakar and Snow, 2020). ENMs are used in almost every technological area, from quantum computing to agriculture (Kah et al., 2018). Nanotechnology is a critical component in the modern world and supporting many industries. ENMs can be broadly grouped based on the morphology such as 0 (quantum dots), 1 (nanorods), 2 (graphene), or 3 (fullerene) dimensions and their composition, such as carbon or metal-based nanomaterials (Jeevanandam et al., 2018). However, these two broad classifications of ENMs are very much overlapping.

2.2.2.1. Morphology-based classification of ENMs. This classification of nanomaterials is based on the movement of an electron within the NMs 


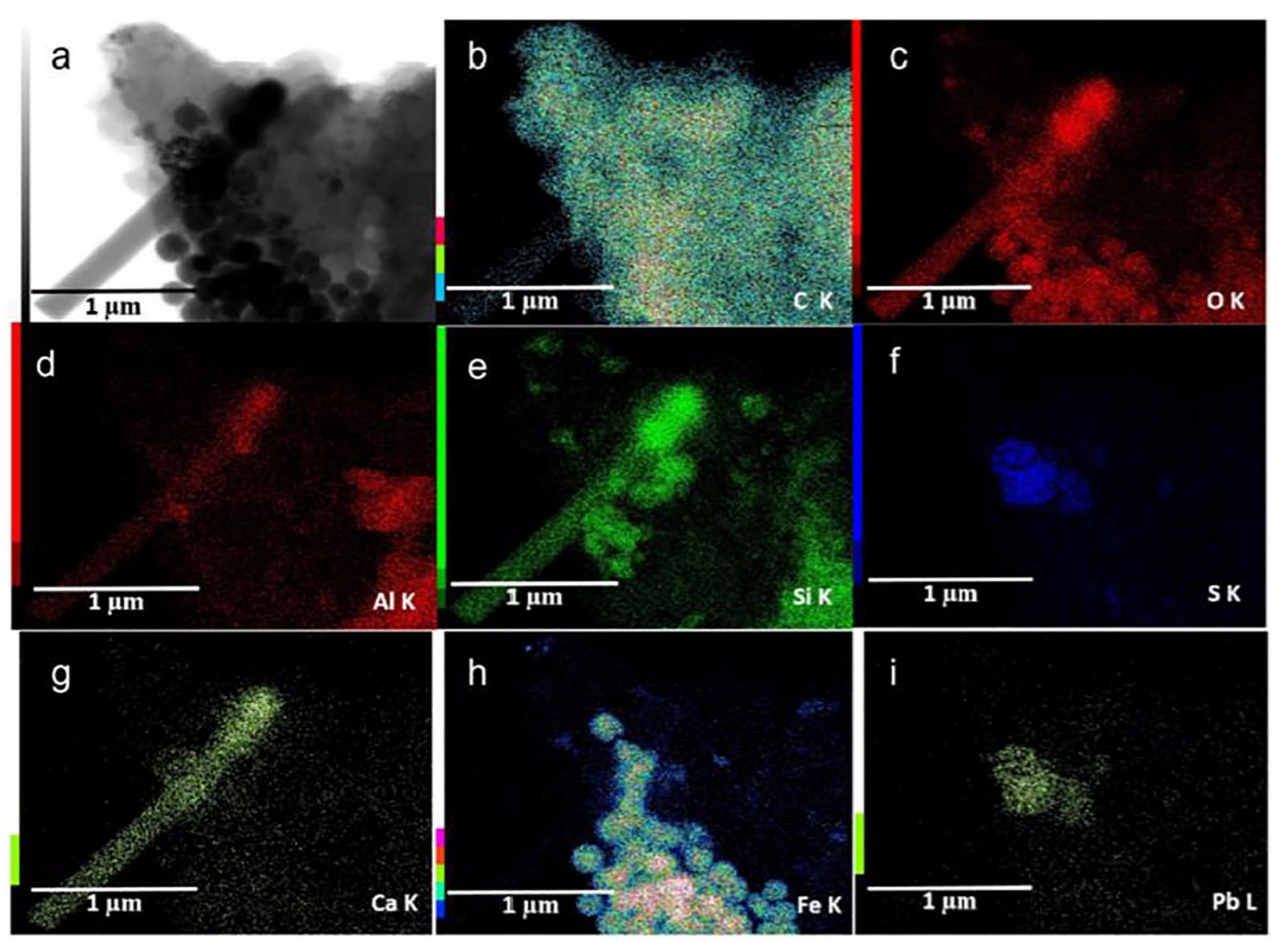

Fig. 3. Transmission electron microscopy (TEM) and X-ray energy dispersive spectroscopy (X-EDS) maps of a typical NM aggregate in a carbon matrix found in a $\mathrm{PM}_{2.5} \mathrm{sam}^{-}$ ple collected during a hazy day in Shanghai, China: (a) bright field micrograph; and (bi) elemental maps of $\mathrm{O}, \mathrm{Al}, \mathrm{Si}, \mathrm{S}, \mathrm{Ca}, \mathrm{Fe}$ and $\mathrm{Pb}$, respectively. These analyses indicate the occurrence of iron oxide ( $\mathrm{c}$ and $\mathrm{h}$ ), galena, $\mathrm{PbS}$ ( $\mathrm{f}$ and $\mathrm{i}$ ) and $\mathrm{Ca}_{2} \mathrm{SiO}_{4}$ (c, e and g) nanomaterials. Iron oxides were identified as magnetite NMs using their selective area electron diffraction (SAED) patterns (data not shown). Reproduced from Baalousha et al. (2016) with permission from Elsevier.

(Jeevanandam et al., 2018). Fig. 4 shows representative examples of different morphology-based classification of NMs reproduced from Jeevanandamet al. (2018). Fig. 4 shows (A) nonporous palladium nanoparticles as an example of zero (0) dimension (D), (B) for 2D graphene nanosheets are shown, (C, D) shows silver nanorods and polyethylene oxide nanofibers, respectively for example of 1D, and (E, F) depicts 3D NMs of zinc oxide nanowires and tungsten oxide nanowire network, respectively. Typically, an electron is entrapped in dimensionless space 

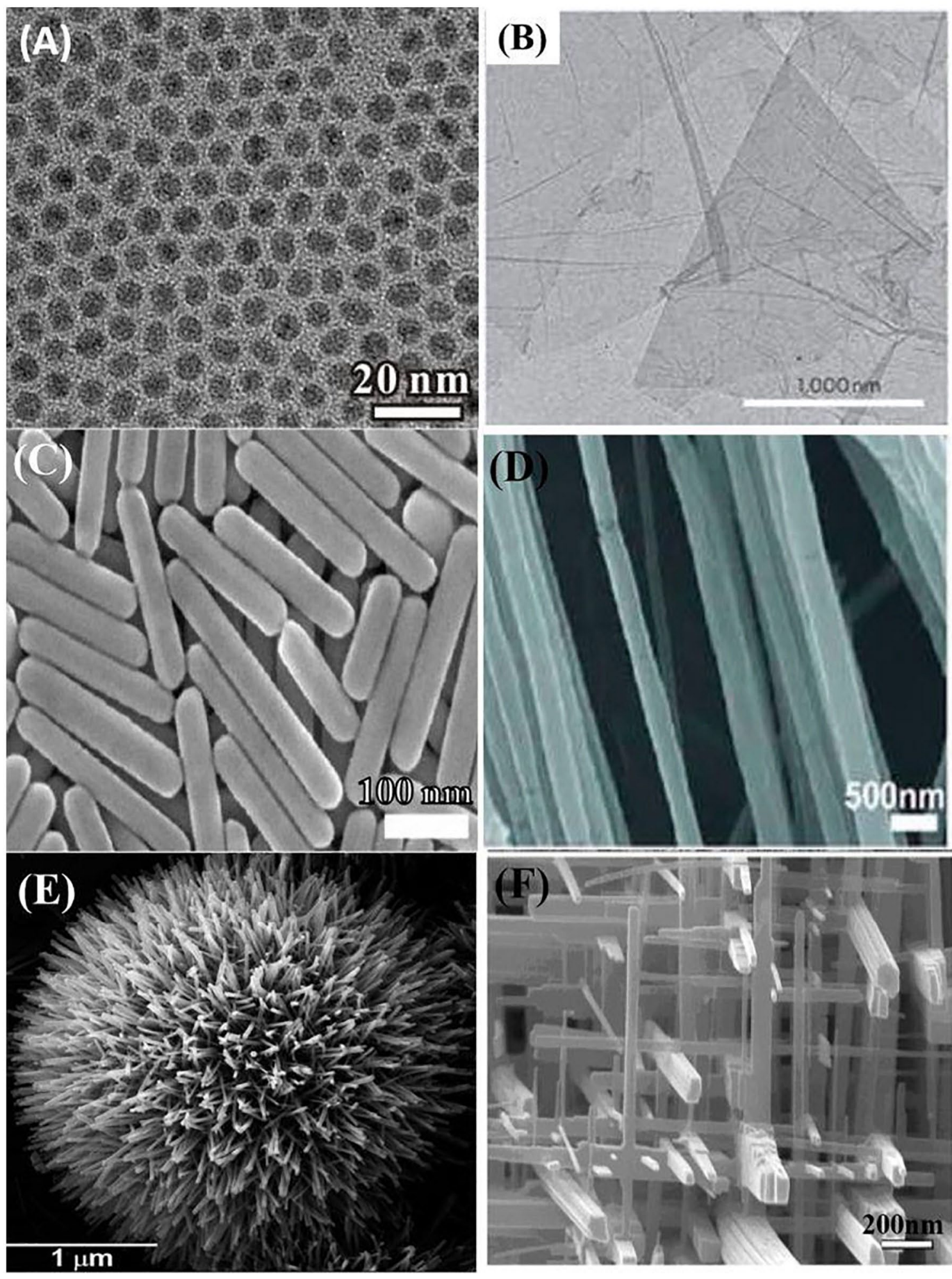

Fig. 4. Nanomaterials with different morphologies: (A) nonporous Pd NPs (OD) (B) Graphene nanosheets (2D) (C) Ag nanorods (1D) (D) polyethylene oxide nanofibers (1D) (E) urchin-like $\mathrm{ZnO}$ nanowires (3D) $(\mathrm{F}) \mathrm{WO}_{3}$ nanowire network (3D). Reproduced from Jeevanandam et al. (2018) with permission from Beilstein Journal of Nanotechnology. 
in 0D NMs, has a unidirectional space for 1D NMs, bi-directional and multidirectional space in 2D and 3D NMs, respectively (Jeevanandam et al., 2018). Zero (0) and 1D materials are widespread and are produced in significant volume for commercial usage. Two dimensional (2D) nanomaterials represent a relatively new and attractive high member among numerous nanomaterials. Graphene is a well-known example of 2D NM. 2D NMs and their nanocomposites have well exhibited outstanding physical, chemical, optical, and electronic properties, which promote their extensive applications in catalysis, energy, sensing, bioimaging, antibacterial, drug delivery, and therapy (Su et al., 2019; Tan et al., 2017; Wang et al., 2012). The first two-dimensional atomic crystal, graphene, possesses many superior physical and chemical properties and justifies its nickname of "miracle material" (Fang et al., 2015). The 3D printing is a forming technology based on a digital computer model, which constructs 3D structure by "bottom-up" discrete cumulative method. Three-dimensional printing can build structures with precisely controlled geometry and size that can be used in electronic, chemical field, and medicine (Jiang et al., 2019). 3D macrostructures are constructed via self-assembly of 2D graphene oxide (GO) and 1D carbon nanotubes (CNTs), and a study found that the 3D microstructures exhibited superior adsorption capabilities to emerging and traditional pollutants (Shen et al., 2017). CNT was tested to adsorb $\mathrm{ClO}_{4}{ }^{-}$, and it was found that the adsorption of $\mathrm{ClO}_{4}^{-}$into different CNTs increased in the order multi-walled CNTs $<$ single-walled CNTs $<$ double- walled CNTs (DWCNTs) (Fang and Chen, 2012).

2.2.2.2. Composition-based classification of ENMs. ENMs classified based on composition can be synthesized from carbon sources such as carbon nanotubes, organic NMs such as lipid or polymer-based NMs, and metals such as nano zero-valent iron (nZVI) or metalloids such as cadmium sulfide (CdS) nanorods. Zero-valent metal NMs are generally produced from the bottom-up approach and highly controlled for tailor-made morphology. The nanocrystalline structure can be defect-free. These ENMs have extensive usage in optoelectronics (Gad and Hegazy, 2019), and zero valences along with size constriction give them high reactivity, making them also useful for water remediation (e.g., nZVI) (Kanel et al., 2008, 2006a, 2006b; Kanel and Choi, 2007; Zou et al., 2016). Gold (Au) and Aubased NMs are used in sensor applications (Xiao et al., 2020). Metals and 
metalloid oxides, carbides, sulfides, and carbonates are included in ceramic NMs. These NMs can be chemically inactive, heat resistant, which make them viable material for different uses (Thomas et al., 2015). Chipset and electronics use semiconductor NMs due to the wide bandgaps in these nanomaterials. Semiconductor NMs have increased processing power or mobile devices. These ENMs can be produced using metals and metalloids. Semiconductor NMs are used in photovoltaics, photoelectron generation, photocatalysis, hydrogen production (Khan et al., 2019). Semiconductor nanomaterials are produced in a wide range of morphology ranging from zero to 3D shapes, as this morphology can help tune across a bandgap.

Carbon-based NMs consists of carbon nanotube (CNT), fullerenes $\left(\mathrm{C}_{60}\right)$ with a diameter ranging from $<1$ to $4 \mathrm{~nm}$. CNTs are massively produced ENMs at around $\sim 270$ tons/yr (Singh, 2016). CNTs possess thermal conductivity comparable to diamond and high electrical conductivity. CNTs are used in microelectronics, medicine, hydrogen fuel cell technology. CNTs are also used in water treatment (Kanel et al., 2016; Pokhrel et al., 2017). There are concerns over the health implications from exposure to CNTs that could be comparable to exposure to asbestos (Christou et al., 2016). Graphene oxide (GO), an oxidation derivative of graphene, is considered as a recently-developed nanomaterial that is most attractive for use in biomedical applications. Although the prospect of numerous applications for GO fuels additional development, concerns about its biosafety regarding human exposure and environmental consequences remain. A recent review systematically summarized the research on GO toxicity both in vitro and in vivo, followed by in-depth discussions about the toxicological mechanisms (Chen et al., 2019). Another group of carbon-based NMs consist of polymeric organic molecules such as chitosan, cellulose, polylactic acid, polyacrylonitrile, polyhydroxyalkanoate, and poly(lactic-coglycolic acid) (Hauser et al., 2019). These NMs can have various morphology, but generally are nanospheres or nanocapsules (Khan et al., 2019). These NMs are mostly used in the medical field as they are biodegradable and biocompatible. As delivery vehicles, polymer-based NMs can be used to transport antigens, proteins, drugs, and vaccines without needles and may have lower cytotoxicity than alternatives (Han et al., 2018; Hashem and Gonzalez-Bulnes, 2020). 


\section{Nanomaterials in the environment}

NMs, both natural and synthetic, have multiple pathways through which they can interact with different environmental compartments (Table 1). NMs commonly occur in the air, such as incidental NMs (INMs) are likely to be at higher levels in urban areas. NMs can accumulate and make their way to different water sources or in soils around landfills, industrial discharges, municipal wastewater, or can be generated by natural processes in these environmental compartments (Baalousha et al., 2016; Malakar and Snow, 2020; Westmeier et al., 2018). Fig. 5 presents the pathway NMs may follow to make their way to different aquatic environments. NNMs, which are of high volume and readily available in nature and from the cosmos, can occur in precipitation and find their way to surface water sources or recharged to groundwater. NNMs are likely to be found in the soil microbial ecosystem and can remain suspended as dust

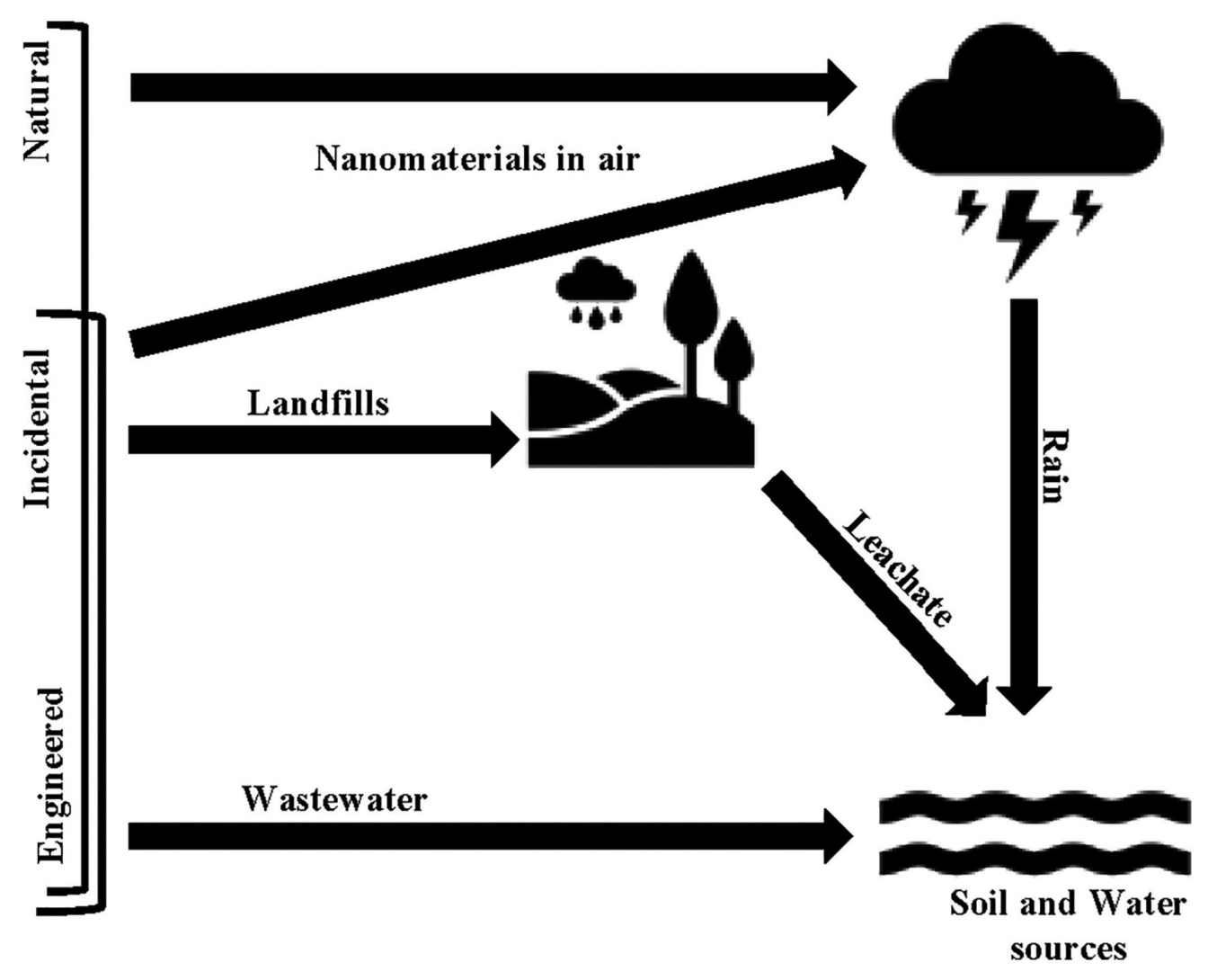

Fig. 5. Transportation pathways of natural and artificial (incidental and engineered) nanomaterials to soil and water sources. 
in the air for extended periods (Ermolin et al., 2018). Similarly, factory discharge waste in the air or automobile gases, or sewage from landfills or wastewater facilities can make their way to natural water bodies and soil either by precipitation from air-bound particles or point of discharge sources (Baalousha et al., 2016). Commercially-produced NMs can be discharged into the aqueous environment during their production stage or during the end-stage of their life cycle as waste products. These ENMs can slowly migrate to surface and groundwater environments or remain in soils to later be taken up by plants or animal-based food products. Wastewater is considered to be one of the primary vectors to distribute ENMs into the natural environment.

\subsection{Natural nanomaterials in the environment}

Nature is a skilled nanotechnologist (Griffin et al., 2018), and a massive volume of NNMs are present naturally. However, their fate, transformation, and potential toxicity are usually ignored (Ermolin et al., 2018). NNMs have been overlooked mainly due to the absence of suitable analytical tools to measure them in a complex natural environment reliably and reproducibly (Malakar and Snow, 2020). As Earth evolved to the present form, NNMs have been part of that evolution (Hochella et al., 2019), which is an additional reason why there is a lack of understanding of their effect in the environment. Nanogeosciences development has brought in advanced tools to understand fate, potential toxicity, and transportation of NNMs and help understand the multifaceted role of NNMs in the ecosystem.

NNMs from volcanic ash, forest fires, lightning, or formed in the outer space can easily be present in the air. Naturally occurring multiwalled carbon nanotubes, generated from soot, have been found in the air of size ranging between 15 and $70 \mathrm{~nm}$ (Griffin et al., 2018). Silicon dioxide nanomaterials can also make their way to the atmosphere from volcanic eruptions; these oxide NMs in the air can cause eye irritation (Lungu et al., 2015). Other forms of nanomaterials can also be suspended in air and carried across the planet with the wind (Ermolin et al., 2018).Mercury nanoparticles, produced naturally, can also be airborne, which can easily make their way to other natural resources such as soil and water (Ghoshdastidar and Ariya, 2019). NMs, both natural and synthetic, can be airborne by binding to fungal spores and exposed to humans (Westmeier et al., 2018). 
Precipitation can deposit air-suspended nanomaterials into ground and surface water sources. NNMs from volcanic ash can quickly spread to different surface water sources (lakes, rivers, sea, and oceans) by winds and downpour (Fig. 5), which can increase toxicity risk (Ermolin et al., 2018; Hochella et al., 2019). Various natural water resources can contain volumes of NNMs in a dispersed form such as groundwater or aquifers with NNMs concentration in the range of low $\mathrm{mg} \mathrm{L}^{-1}$. Surface water is also known to contain NNMs, in various size regime (Baalousha et al., 2019; Westerhoff et al., 2018). Major metals in the oceans can occur at the nanoscale size regime. For example, $80 \%$ of the iron constitutes in the size fraction of $20-200 \mathrm{~nm}$, almost $100 \%$ of manganese is below 20 nm (Hochella et al., 2019), which are known to impact redoxbased biogeochemical cycles. However, the concentration of NNMs can be too low to recognize their toxicity in the environment (Sharma et al., 2015). Recent studies confirmed the toxicity of naturally formed silver NMs formed by light and thermal energy in environmentally relevant conditions and are influenced by change in $\mathrm{pH}$, oxic/anoxic conditions, the formation of reactive oxygen species (ROS), and stabilization from natural organic matter (NOM) (Adegboyega et al., 2016; Sharma and Zboril, 2017; Zhang et al., 2015). Further, iron redox species (Fe(II)/ Fe(III))were found to accelerate the production of Ag NMs (Sharma and Zboril, 2017). Gold (Au) NNMs is also stabilized in water by NOM and can be formed by the reduction of $\mathrm{Au}$ ions (Yin et al., 2014). The toxicity of NNMs mainly arises from their dissolution and release of metal ions, which is prevalent under anoxic conditions and depends on the kinetics and mechanism of dissolution under environmentally relevant oxic/ anoxic conditions. However, NNMs can also serve as an essential nutrient source; for example, volcanic ash NMs serves for phytoplanktons but can also increase toxicity levels (Maters et al., 2016).

Studying nanoscale biogeochemical processes introduced by various NNMs is a challenging task (Hochella et al., 2019; Sun et al., 2017). The formation of NNMs containing geological materials and their influence to control different biogeochemical cycles in the complex environment are still puzzling (Wang, 2014). Recent studies have indicated that NNMs may not be a direct risk as a contaminant but can control trace elements such as arsenic contamination levels in different water sources. Most NNMs surface contains a layer of organic matter, which provides a net negative surface charge and enhances stabilization by double-layer 
formation (Vindedahl et al., 2016). The increased colloidal stability can dictate NNMs transportation in different water sources, thereby controlling the mobility of bound trace elements onto the NNMs. The most critical parameter for the mobility of NNMs is size, surface charge, and the Stokes settling velocity (Kretzschmar and Sticher, 1998; Wagner et al., 2014). In surface water, NNMs aggregation is primarily controlled by the surface charge. Gravitational forces can initiate precipitation after aggregation processes. NNMs mobility in groundwater sources is dependent on particle deposition, size exclusion, redox potential, $\mathrm{pH}$, ionic strength of the bulk solution, along with a surface charge of NNMs (Wagner et al., 2014). The broad impression is that NNM-metal ion complexation limits elemental mobility, bioavailability, diminish contaminant levels, and thereby limiting the detrimental effects of trace elements in different water sources. However, reductive dissolution of NNMs, for example, can release trace elements to water bodies, elevating their concentration in the water source above maximum contamination levels (Erbs et al., 2010; Malakar et al., 2020; Voegelin et al., 2019).

The mobility of NNMs such as metal hydroxides and oxides lies in their tendency to form stable complexes with trace elements in the water. This behavior may control the bioavailability of essential and toxic metal ions in natural water sources and soil. This complexation can result in the formation of the inner-sphere complex between NNMs and trace metal ions. Factors such as $\mathrm{pH}$, redox condition, ionic strength, the effect of NM interaction, and concentration of humic matter in comparison to NNMs play an essential role in complex formation. These interactions can be significant in understanding the impact of NNMs in soil. NNMs play a critical role in other related processes at the aqueous-soilorganism interface (Hochella et al., 2019).NNMs present in the soil can impact rhizosphere processes and can also end up in the food products. However, there are severe limitations to study natural nanomaterials interaction in the natural environment (Ermolin and Fedotov, 2016; Malakar et al., 2019). The rapid advancement of analytical techniques to measure NMs makes it possible to understand the diverse role of NNMs in climate change, microbial-soil-rhizosphere interfaces, and different cycles of nature. Presently there is a substantial knowledge gap regarding the chemical composition of NNMs and their life cycle in natural systems. The fate and behavior of NNMs call for further research as NNMs can add to the complexity of understanding the life cycle of NMs in different natural resources. 


\subsection{Synthetic nanomaterials in the environment}

The end-stage in the life cycle of synthetic NMs is through discharge to the environment. Similar to NNMs, tracing synthetic NMs in a different natural environment is complex and challenging. However, the definitive source and sink of synthetic NMs can potentially help in tracking the life cycle in the natural environment. Synthetic NMs, both incidental NMs (INMs), and engineered NMS (ENMs) can potentially be released to the atmosphere at the source of production and can remain suspended for a prolonged period. Road vehicles are considered the primary contributor of synthetic NMs in the air, specifically in urban busy traffic areas (Baalousha et al., 2016). These synthetic NMs can be found embedded in $\mathrm{PM}_{2.5}$ samples, and one example is presented in Fig. 3, with signatures of iron oxide, galena, and calcium silicate (Baalousha et al., 2016). The atmospheric release of synthetic NMs, incidental, or engineered, is considered to be the most important pathway for human exposure (Baalousha et al., 2016). Concurrent existence of $\mathrm{C}_{60}$ was found in air and water samples collected in the Netherlands (Bäuerlein et al., 2017). The same study found that between 1 and $6 \%$ of the total mass in the air samples were particles below $100 \mathrm{~nm}$ (Bäuerlein et al., 2017). NMs release dynamics reports project the necessity for environmental risk assessment of synthetic NMs (Sun et al., 2017, 2016).

Synthetic NMs suspended in air can follow a similar pathway as followed by NNMs and end up in various soil and water sources shown in Fig. 5 (Malakar and Snow, 2020). Urban runoff can have high volumes of synthetic NMs, which can be tracked in stormwater and end up in wastewater treatment facilities, which can further infiltrate groundwater, and surface runoff can pollute surface water sources (Wang et al., 2020). ENMs interact with the various constituents of different water bodies (Baalousha et al., 2016). The different interactions include homo and hetero agglomeration, physical- and chemisorption, flocculation, precipitation, and transformation (Koelmans et al., 2015a).Wastewater discharge after treatment has a substantial amount of ENMs and releases these ENMs to water sources (Fig. 5) (Kunhikrishnan et al., 2015). Waste and biosolids can also contain ENMs which can easily leach from landfills and reach surface water or infiltrate to groundwater (Fig. 5). The release pathway of synthetic NMs to the environment can be from direct usage or indirectly through landfills and wastewater effluent. ENMs can transform during any of these phases of release, affecting their properties 
(Gogos et al., 2019; Kaegi et al., 2015). These changes are primarily observed in the indirect release (Bundschuh et al., 2018). These released NMs can be retained in different water bodies (Koelmans et al., 2015b). ENMs entry to the environment can be at the production phase, at the usage phase, and release after dumping (Bundschuh et al., 2018). However, it is expected that ENMs, unlike INMs, are mostly released in the latter two stages of synthetic NMs life cycle (Barton et al., 2015).

Incidental NMs such as $\mathrm{TiO}_{2}$ used in pigments, paper industry, paint industry are found in water sources by the peeling of paints and consequent mobilization (Sani-Kast et al., 2015). The studies further monitored that $\mathrm{TiO}_{2} \mathrm{NMs}$ accumulation occurs mostly in sludge-treated soils than by sediments and landfills. $\mathrm{TiO}_{2}$ is released mainly to the environment from wastewater, accounting for $85 \%$ of total discharge (Arvidsson et al., 2018). ZnO NMs are also known to accumulate in landfills and soils from the disposal of medicine, electronics, and cosmetics such as sunscreen utilizing ZnO (Durenkamp et al., 2016), and the major pathway of release is from wastewater discharge (Kirkegaard et al., 2015). Carbonbased incidental NMs such as CNTs release occurs primarily during the production phase (almost $90 \%$ of total) and can directly deposit at landfills (Sun et al., 2016). Incidental metal NMs such as silver can also be released to the environment during the production phase. Silver NMs can also accumulate in wastewater, biofilm reactors, and landfills (Alizadeh et al., 2019; Bundschuh et al., 2018; Durenkamp et al., 2016). Silver NMs embedded in fabrics, which is around $20 \%$ to $100 \%$ of total particle content, are released during laundry and observed in the wastewater stream (Choi et al., 2017; Kaegi et al., 2015).Wastewater treatment plants serve as a primary release pathway for ENMs. These treatment plants have a crucial role in the redistribution of ENMs to different water bodies. Still, there is a significant knowledge gap about the fate, transformation, mobility, and behavior of ENMs in the complex matrix of wastewater.

Currently, environmental applications for nanotechnology-based products are increasing. These applications for various purpose releases ENMs directly to the environment such as groundwater nano remediation (Bardos et al., 2018), nano pesticides, and nano fertilizers application (Kah et al., 2018). Nanoscale zero-valent iron (nZVI) particles are used for groundwater remediation (Soares et al., 2018; Zou et al., 2016). Direct injection of nZVI is done for point decontamination of groundwater sources (Soares et al., 2018; Stefaniuk et al., 2016). Direct injection into an aquifer can have unintended consequences as nZVI can interact 
with microbes (He et al., 2017), and can be harmful to groundwater bacteria by impacting prevailing biogeochemical cycles in the subsurface (Lei et al., 2016). A recent study by Crampon et al. found that nZVI can negatively impact bacterial abundance and affect groundwater ecology (Crampon et al., 2019). Other studies have found nZVI to be toxic towards other living organisms and were found to be bioaccumulated in bacteria and bacterial cell walls (Jiang et al., 2018; Wille et al., 2017; Xue et al., 2018). ENMs residues post-treatment is presumed to be consumables (Good et al., 2016; Simeonidis et al., 2016; Troester et al., 2016), but reactivity, mobility, and relative stability of ENMs in water can make them toxic to humans. Therefore, further evaluation of toxicity due to direct consumption is recommended.

A recent study tried to identify the fate of ENMs used in water treatment in five different water sources including freshwater and groundwater (Sousa and Ribau Teixeira, 2020). The commonly used ENMs such as $\mathrm{TiO}_{2}$, Ag, and $\mathrm{ZnO}$ ENMs, in water treatment processes, were considered and was found in hazardous amounts after the final membrane filtration process (Sousa and Ribau Teixeira, 2020). ZnO ENMs release zinc ions by dissolution and generate ROS. Different amounts of ZnO NMs can travel in saturated porous media at different distances depending on solution pH (Kanel and Al-Abed, 2011). Nanoadsorbents utilized for drinking water treatments may have health effects on humans and other living organisms if not removed in the final product (Simeonidis et al., 2016).

In water, ENMs can achieve stability through interaction with NOMs, such as humic matter (Grillo et al., 2015). ZnO ENMs show higher mobility in the presence of humic substances due to the reversal of surface charge (Yecheskel et al., 2016). Humic substances have been shown to stabilize multi-walled CNTs (Boncel et al., 2015; Gao et al., 2018). Further, exposure to CNTs has been shown to produce toxic effects through the co-occurrence of reactive oxygen species (ROS) in freshwater (Lawrence et al., 2016). Fullerene mobility is significantly affected in the presence of iron oxyhydroxide, precisely alpha form (Ghosh et al., 2016). Humic substances play a vital role in stabilizing ENMs in different aqueous mediums. Still, other parameters like the presence of other NNMs, $\mathrm{pH}$, redox conditions also play a significant role in determining their stability, mobility, and transformation in these complex systems. The multiparticle design of the natural environment makes it critical and poses a challenge in understanding the life cycle of ENMs in complex ecosystems (Lowry et al., 2012). 
The potential toxicity of ENMs make them potential pollutant in different water sources, but there is a lack of comprehensive datasets and monitoring tools to observe NM levels in drinking water (Westerhoff et al., 2018). Surface water sources, which have the largest potential to be polluted by NMs, are the common sources of raw drinking water in most developed nations. Different surface water sources, treatment facilities, and point of use sites were studied utilizing material-flow model and field data to predict ENMs presence in drinking water, and chances of ENMs in drinking water was found to be low (Westerhoff et al., 2018). However, a recent experimental study on 44 tap water samples from Phoenix, Arizona by the same research team found lead, tin, iron, and copper with average concentrations ( $\mathrm{ng} \mathrm{l}^{-1}$ ) of $1.2 \pm 1.3,1.8 \pm 3.0,88 \pm$ 144 , and $69 \pm 45$, respectively representing a minimum of $0.4 \%, 18 \%$, $16 \%$ and $0.2 \%$ of particles from the corresponding total dissolved concentrations (Venkatesan et al., 2018). Fig. 6, reproduced from the study by Venkatesan et al. (2018), reveals the average particulate content from 36 tap water collected at Phoenix, Arizona, as seen under single-particle inductively coupled plasma mass spectroscopy (spICP-MS). In Fig. 6 , the average particulate and background of $(a, b)$ lead, $(c, d)$ iron, and $(\mathrm{e}, \mathrm{f})$ tin, are shown respectively. The black bar represents the concentration in the first $125 \mathrm{ml}$ sample collected immediately after turning on the faucet. The grey bar represents the concentration in the subsequent $500 \mathrm{ml}$ samples, collected after running the tap for a minute. It can be seen that particles were observed in both initial and secondary samples for all three elements, indicating the presence of NMs. However, the particle concentration of lead and tin was much lower compared to iron. Another report on surface water from the Dutch rivers: Meuse and Ijssel, confirmed the occurrence of Ag and cerium oxide ENMs and $\mathrm{TiO}_{2}$ microparticles. The Dutch study found that concentration of silver NMs was $0.8 \mathrm{ng} \mathrm{l}^{-1}$ with an average particle size of $15 \mathrm{~nm}$, for cerium oxide, it was $2.7 \mathrm{ng} \mathrm{l}^{-1}$, with an average particle size of $19 \mathrm{~nm}$, and $\mathrm{TiO}_{2}$ was found in an average concentration of $3.1 \mu \mathrm{g} \mathrm{l}^{-1}$ and an average particle size of $310 \mathrm{~nm}$ (Peters et al., 2018). Polymeric ENMs such as polyacrylonitrile, chitosan, and hydroxyapatite have been found in freshwater and soil (Hauser et al., 2019).

Synthetic NMs present in the soil can be part of different agricultural products. ENMs uptake by different crops and their impact on irrigation water quality has been elaborated in recent reviews (Gupta and Xie, 2018; Malakar et al., 2019). The review points out that ENMs in plants 

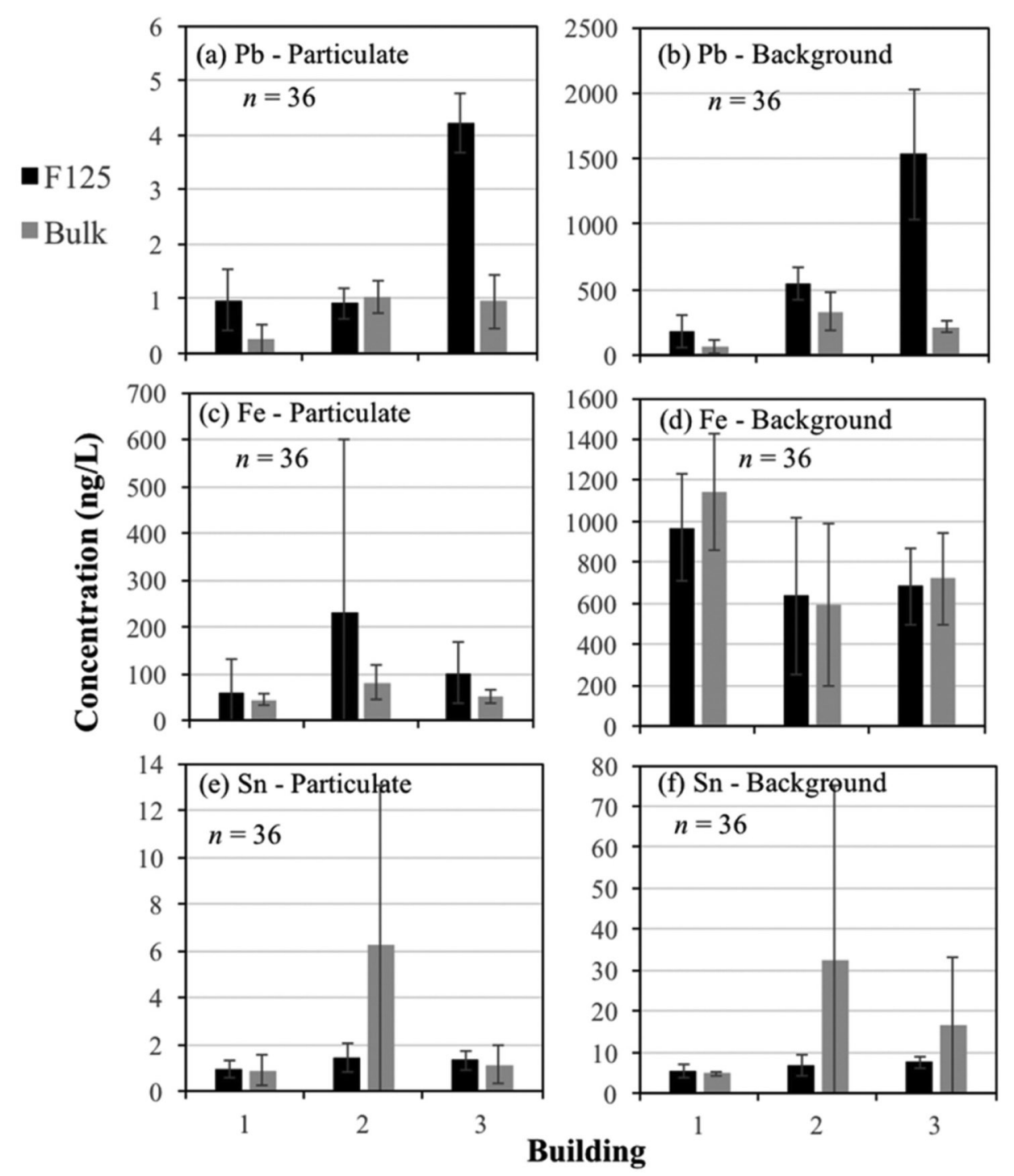

Fig. 6. Average particulate $(\mathrm{a}-\mathrm{Pb} ; \mathrm{c}-\mathrm{Fe}$; $\mathrm{e}-\mathrm{Sn})$ and background $(\mathrm{b}-\mathrm{Pb} ; \mathrm{d}-\mathrm{Fe}$; $\mathrm{f}-$ $\mathrm{Sn}$ ) elemental concentrations determined by spICP-MS in the initial 125-ml fractions (black bar) and secondary $500 \mathrm{ml}$ fractions (bulk; grey bar) of tapwater collected from the three buildings. ' $n$ ' represents the number of tap water samples analyzed. Error bars represent plus/minus one standard deviation Venkatesan et al. (2018) with permission from The Royal Society of Chemistry.

can be passed to humans through the consumption of food, and their implication to health is unknown (Malakar et al., 2019). Even nano pesticide and fertilizer residues can end up in the crops and make their way to the food chain and act as an essential exposure pathway (Malakar et al., 2019). Assessment of the fate of ENMs in soil and the unsaturated zone 
is dependent on the surface functionality of ENMs (Rahmatpour et al., 2018). ENMs are generally found in the air-water interface if they have a hydrophobic surface, and if the surface is hydrophilic, ENMs are more likely to occur in the water film. The surface charge on the ENMs can facilitate their retention in the unsaturated zone (Hoggan et al., 2016). Similar to NNMs, ENMs movement and flow pattern is dependent on $\mathrm{pH}$, redox conditions, and ionic strength. These parameters are dependent on the wetting/drying cycles in the unsaturated zone. This underlines the importance of understanding the conditions in the soil environment for predicting the transport of nanosized particles.

Our understanding of the human health hazards related to synthetic NMs in various environmental compartments is mostly inadequate. There are multi-fold reasons such as nanoscale size, transient nature of the particles, reliable monitoring tools, which limit understanding of synthetic NMs impact as a pollutant in different water bodies, soil, and air. These knowledge gaps need to be addressed to comprehend the release and exposure pathways of synthetic NMs and their long-term impact on the environment.

\section{Sampling and analysis of NMs in the environment}

The environmental behavior of NMs is unlike ionic species, and their properties vary considerably from a bulk counterpart. The nanoscale size regime studies the NMs life cycle in complex environmental compartments consisting of water, soil, air, sediment, and biota. NMs have unique properties and studying them requires specialized analytical tools. A recent review reported on sampling and analysis of NMs (Saleh, 2020). Recent analytical development for nanogeosciences and nanotechnology usage for environmental research has garnered visibility and support (Hochella, 2008; Malakar and Snow, 2020). Modern-day analytical nanoscience instrumentation provides cutting-edge tools that have helped outline new understandings about NMs. Specialized sampling techniques developed by environmental scientists can be used for studying the occurrence and potential impact of NMs, which can be complemented by advanced analytical tools (Lead et al., 2018). Controlled laboratory conditions can also be utilized to simulate the natural environment and study specific NMs without other interferences, which can 
help better understand the fate, transformation, and impact on the environment (Malakar and Snow, 2020).

Electron microscopy, such as transmission electron microscopy (TEM) and scanning electron microscopy (SEM), is a key tool for analyzing NMs using direct visualization of NMs within the complex matrices. Visualization can help elucidate morphology, size, and agglomeration state of the concerned NMs (Laborda et al., 2016). Further, electron microscopy can be coupled with energy dispersive X-ray spectroscopy, which can help understand the NM's elemental composition both qualitatively and quantitatively. Advanced techniques, such as scanning TEM (STEM), environmental SEM (ESEM), cryo-TEM, are very well suited for environmental samples. However, differentiating natural from synthetic NMs is still challenging utilizing these techniques. Optical microscopy techniques using hyperspectral-enhanced dark field microscopy (HEDFM) and confocal fluorescence microscopy (CFM) can be used to study NMs in biological samples as electron microscopy may not be suitable for such samples (Brown et al., 2018). However, optical microscopy may be limited to fluorescent NMs.

Atomic and isotope spectrometry, specifically inductively coupled plasma mass spectroscopy (ICP-MS), is one of the most robust tools to quantify NMs in different matrices, especially in aqueous samples. The low detection limits of ICP-MS makes it a method of choice and is being developed continuously to couple with other systems for easier detection of NMs such as single-particle ICP-MS (spICP-MS). Here, a low concentration of NMs dispersed solution is introduced such that a single pulse is equivalent to one NM, and the intensity of individual ion can tell about the size of the particle (Meermann and Nischwitz, 2018). spICP-MS is an emerging analytical technique, and considerable development will be required to make it more viable and cost effective. New techniques such as multi-collector (MC-ICP-MS) and time of flight (ICPTOF-MS) are being developed to overcome the shortcomings of spICPMS (Meermann and Nischwitz, 2018). Low concentrations of NMs in complex environmental matrices require prepurification where individual NMs are separated and purified before analysis. Enrichment ensures more accessible and more accurate detection and characterization of NMs. Field flow fractionation (FFF) has been widely used to extract NMs of low size from water and separate before analysis using ICP-MS (Moreno-Martin et al., 2017). Other separation techniques include size 
exclusion chromatography, hydrodynamic chromatography, and capillary electrophoresis. However, these techniques may be prone to clogging and may not be highly sensitive at smaller dimensions.

Light scattering techniques, such as dynamic light scattering (DLS) and nanoparticle tracking analysis (NTA), are inexpensive and provide a method for characterizing particle size distribution in liquid. However, these techniques may not be useful for polydisperse, heterogeneous samples and cannot provide information about elemental composition or shape (Luo et al., 2018). NMs in the atmosphere can be trapped and concentrated within filter materials (Baalousha et al., 2016) and can be analyzed using the above-discussed techniques. Particle counters are also utilized for an ongoing study of NMs in air, where the number concentration of NMs in air samples is measured temporally and can have size resolution capabilities. A scanning mobility particle sizer (SMPSTM) 2.5-1000 nm and fast mobility particle sizer (FMPSTM) 5.6-560 nm are examples of high-resolution particle analyzers providing low detection limits and continuous measurement capabilities. However, all these present-day analytical tools still lack high sensitivity and reproducibility to study NMs in the complicated multi-particle environment. Reproducibility, sensitivity, and cost-effectiveness are the primary requirements for making these analytical tools more viable.

\section{Nanomaterial exposure and human health concerns}

Nanotoxicology is a sub-specialty of particle toxicology and mainly deals with toxic effects arising from exposure to NMs. As material properties change considerably at the nanoscale, these changes may give rise to effects unique to a specific size regime which are completely absent in the bulk material. There are lack of studies on the impact of natural NMs on human health, and most research is focused on synthetic NMs, specifically ENMs. Recently, multiple review papers on ENMs reported their properties, route of exposures, interactions with plants and animals, and environmental applications (Basei et al., 2019; Basinas et al., 2018; Coman et al., 2019; Eivazzadeh-Keihan et al., 2019; Jawed et al., 2020; Lewis et al., 2019; Schulte et al., 2019; Taghipour et al., 2019; Wei et al., 2019). Cronin et al. (2020) reported ENMs effects on human immune systems and presented a review of nanosafety assessment (Cronin et al., 2020). 
The review article primarily focuses on the exposure pathway of different NMs from the air, water, and food (- where NMs are deliberately added or NMs present in the soil is taken up by food products), as key vectors. The life cycle of NMs in the human body, their residence times, and fate to different human organs can be dissimilar (Fig. 7) and highly dependent on the exposure pathway, physical and chemical properties of the NM. The extensive production and use of ENMs have raised many concerns about their fate, life cycle, and potential toxicity in the environment and to human health (Arvidsson et al., 2018; Bour et al., 2015; Goswami et al., 2017; Ma et al., 2016). Some ENMs can be indirectly carcinogenic by generating reactive species such as ROS (Ganguly et al., 2018;

Pini et al., 2016).

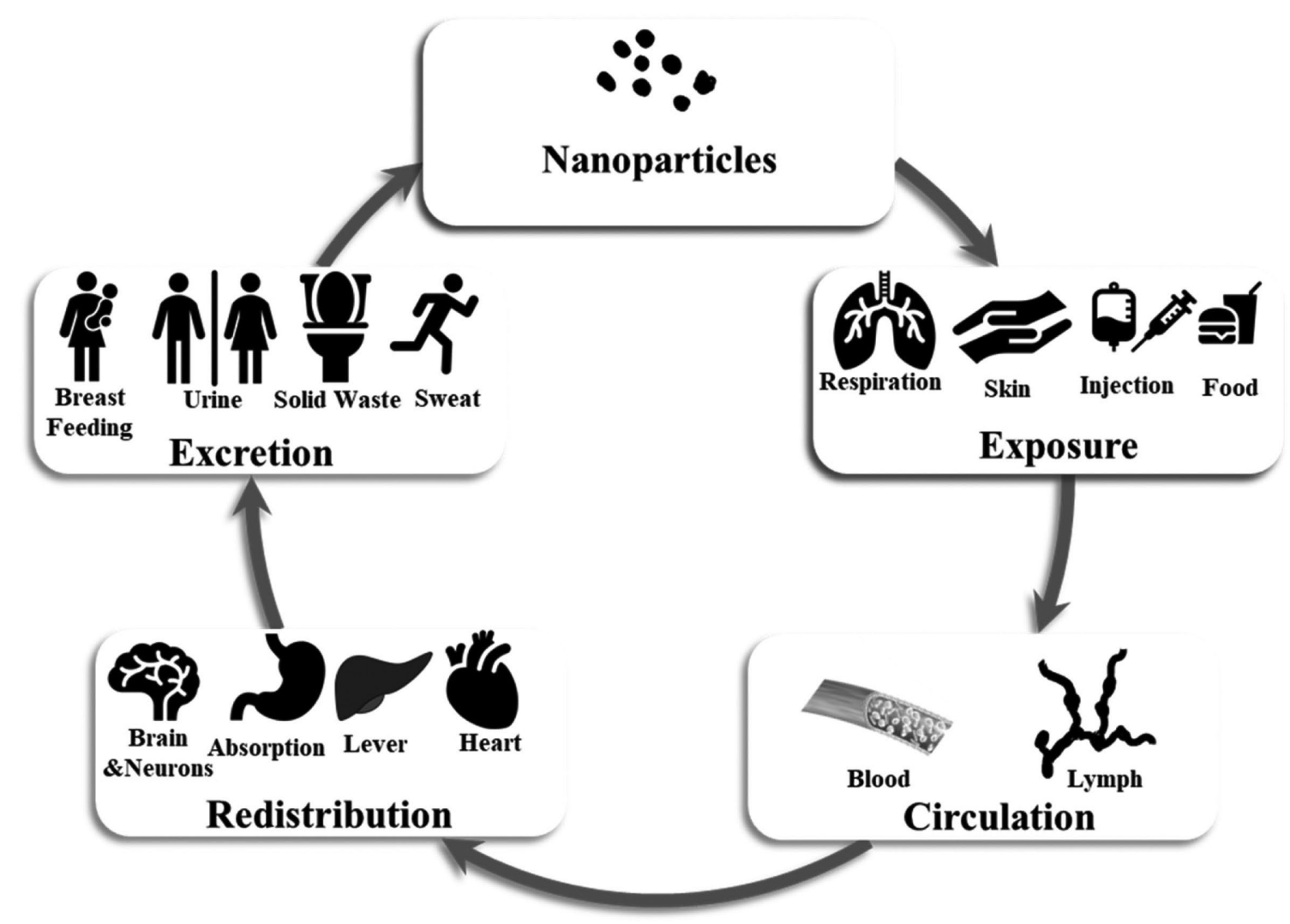

Fig. 7. Exposure pathway, circulation, redistribution, and final excretion of nanomaterials inside the human body. 


\subsection{NMs human exposure pathways}

NM exposure to humans occurs through multifaceted pathways: inhalation, ingestion, penetration through the skin, and injection. Inhalation is considered the primary route of exposure to humans, and therefore the presence of NMs in the air is regarded as a significant health hazard. The air quality index in urban areas can act as a possible indicator of suspended NMs, which can be a cause for a variety of cancers. The proposed threshold exposure amount is dependent on the NM particle density. For example, a given density $>6 \mathrm{~g} \mathrm{~cm}^{3}$ for silver, gold, iron, and their oxides, a proposed exposure threshold is estimated to be 20,000 nanoparticles $\mathrm{cm}^{3}$. For $\mathrm{NM}$ densities $<6 \mathrm{~g} \mathrm{~cm}^{-3}$, such as $\mathrm{TiO}_{2}$ and $\mathrm{ZnO}$, it is estimated to be 40,000 nanoparticles $\mathrm{cm}^{3}$ (Oberbek et al., 2019). Urban air can contain 10,000 to 50,000 nanoparticles $\mathrm{cm}^{-3}$ (Oberbek et al., 2019). These estimated limits can increase multi-fold in NM processing and production industries, which can be a significant concern for workplace safety (Geiser et al., 2017). Leather tanneries can have chronic occupational exposure to INMs likely to be detrimental to human health (Sarwar et al., 2018).

It is estimated that NMs in commercial applications now are in $~ 3000$ products in various sectors (Huang et al., 2017). ENMs such as $\mathrm{TiO}_{2}$ ( $\sim 80 \%)$, $\mathrm{ZnO}(\sim 70 \%)$, silver ( 20\%) are estimated (shown as \%) to be present in personal care products, including baby products (DeMatteis, 2017; Ding et al., 2018) and can be directly exposed to humans when applied to the skin. Moreover, there is an ongoing debate on the potential for the passage of NMs through the skin barrier. Generally, metal NMs are considered to cross over the skin and reach basal layers (DeMatteis, 2017). As skin pores are small, it is evident that smaller particles, specifically <4 nm, can cross over easily (Larese Filon et al., 2015). ZnO NMs are used in the food industry, Silver NMs in the textile industry for deodorizing and antibacterial products, iron oxide NMs are used in paints, and to polish the jewelry, can also be exposed directly from use (Huang et al., 2017; Mantecca et al., 2017).

Another route for exposure is the gastrointestinal tract, where food, food products, and beverages may contain NMs (Gupta and Xie, 2018; McClements and Xiao, 2017). For example, the food coloring agent E171 consists of $\mathrm{TiO}_{2} \mathrm{NM}$ at concentrations between 1 and $5 \mu \mathrm{g} \mathrm{mg} \mathrm{mg}^{-1}$ and may be used in sweets (De Matteis, 2017). $\mathrm{TiO}_{2}$ has also been found in 
chewing gums, confectionery, sauces and dressings, nondairy creamers, and in dietary supplements. Consumption amount of $\mathrm{TiO}_{2}$ is estimated to be around 0.2-0.7 $\mathrm{mg} \mathrm{kg}$ body weight/day in the United States and approximately $1 \mathrm{mg} \mathrm{kg}$ body weight/day in the United Kingdom and Germany (Ropers et al., 2017). The review article by Winkler et al. (2018) summarizes the prevailing knowledge gaps in studying the impact of $\mathrm{TiO}_{2}$ food additive and points out that this food additive's highest exposure can be on children (Winkler et al., 2018). The estimated dietary intake of $\mathrm{TiO}_{2}$ was found to be 1-2 $\mathrm{mg} \mathrm{kg}^{-1}$ body weight/day in children under ten years of age in the United States (Winkler et al., 2018). However, there is a lack of studies for establishing safe upper levels of $\mathrm{TiO}_{2}$ intake as a food additive, and more rigorous evaluation is needed to address this uncertainty. Other commercial labels consumed by humans include food additive E551, E554, E556, or E559, consisting of $\mathrm{SiO}_{2} \mathrm{NMs}$. The Scientific Committee on Food of the European Food Safety Authority has set a limit of 20 to $50 \mathrm{mg} \mathrm{\textrm {SiO } _ { 2 }} \mathrm{NMs}$ consumption for $60 \mathrm{~kg}$ person (De Matteis, 2017; Winkler et al., 2016). Polymeric NMs, used for drug delivery, generally considered to be less toxic, are often also used in medication. There are also few studies on the effects of long-term exposure from these NMs (Jesus et al., 2019). Among polymeric NMs, chitosan is the most studied NM, followed by poly(lactic-co-glycolic acid) (Jesus et al., 2019). Chitosan and poly(lactic-co-glycolic acid) were relatively nontoxic in most studies, though may cause inflammation and oxidative stress in rabbit and mice (Jesus et al., 2019; Moraes Moreira Carraro et al., 2017; Shan et al., 2017). A review article by Jesus et al. (2019) summarizes the hazard assessment of polymeric nano-biomaterials used for drug delivery (Jesus et al., 2019). The review article suggests that human health risk assessment of polymeric NMs is limited to case-by-case evaluation of the literature, and lacks a systematic set of in vitro and in vivo toxicity studies with controls needed to generate a database on the toxicity of polymeric NMs (Jesus et al., 2019). Direct injection of NM is used for biomedical applications for drug delivery (Hashem and Sallam, 2020; Korin et al., 2013; Sykes et al., 2014). Medical use of ENMs has provided encouraging results to fight diseases but may also lead to unwanted consequences (Huang et al., 2017; Wang et al., 2018). The increasing use of nanofertilizers and nanopesticides in food production implies that these contaminants may bioaccumulate in soils and food crops, leading to a potential source of exposure when 
applied or ingested (Iavicoli et al., 2017). The agricultural produce consumed by humans can have elevated levels of NMs, where NMs present in soil can end up in the final product, including meat and dairy products and their toxicological impacts are still not clear (Malakar et al., 2019; Malakar and Snow, 2020).

\subsection{Circulation and redistribution of NMs in the human body}

The various exposure pathways - inhalation, skin penetration, and ingestion - will introduce foreign NMs into the body and, because of their size, can affect organisms at the cellular level, bringing about type-1, 2, and 3 cell death (Ganguly et al., 2018). Fig. 7 shows the possible life cycle of NMs inside the human body, transportation, redistribution, and excretion pathway. It is estimated that shape, size, along with a charge of NMs, can enhance the translocation rate by 60 times through cell membranes (Nangia and Sureshkumar, 2012). At the pH range of the human cells, most NMs can be solubilized (Sajid et al., 2015)' release metal ions, and even generate ROS.

NMs are not easily intercepted in the nasopharyngeal region and quickly make their way into the lungs, prolonging the retention time of NMs in the body (Gupta and Xie, 2018). Once in the lungs, NMs can cross through blood-air-tissue barrier and into the bloodstream and potentially affect other body organs. The dosage of NMs through inhalation can also result in an acute response, leading to vascular dysfunction, thrombosis, and myocardial ischemia (Miller et al., 2017). Inhaled NMs can stay in the body as long as three months or more and make their way out of the body through urine (Miller et al., 2017). The translocation rate to different parts of the body after inhalation is generally higher for smaller particles <10 nm size (Miller et al., 2017).

The large surface area of the gastrointestinal tract can promote adsorption of NMs when ingested and translocate them into the bloodstream (De Matteis, 2017). Further, the dissolution of ingested NMs can occur in the acidic pH of the stomach, and the release dissolved ions such as silver and cadmium can lead to toxic effects (Sukhanova et al., 2018). The size of the NMs particles affects their adsorption rates, and generally, smaller particles can be taken up by endocytosis. Once intact NMs enter the bloodstream, they follow a similar trend observed in the inhalation exposure pathway and create havoc in the organ systems at 
the cellular and sub-cellular level by creating chemically reactive species (De Matteis, 2017). Similarly, when NMs enter via skin penetration, the rate of crossing into the bloodstream is again size-dependent, and smaller NMs can more easily enter and affect various organs of the body. NMs metabolism has been extensively reviewed, and studies have suggested that nanoscale size can help NMs easy transportation in the bloodstream affecting different organs such as lungs, kidneys, liver, and can also occur in the breastmilk of lactating mothers (Cai et al., 2019; Wang et al., 2013, 2018). The small size of NMs allows them to cross the blood-brain barrier, and exposure also leads to neurotoxicity (Boyes and van Thriel, 2020).

\subsection{NMs impact on human health}

The size and chemical composition of NMs are the most significant contributors to promoting toxicity towards humans. Most of the properties that arise in NMs are due to the size confinement, which increases the surface area for a similar volume exponentially; and changes the particles' chemical and physical property. These changes can heighten the reactivity and toxicity of NMs regardless of other factors like composition and shape. NMs smaller than $100 \mathrm{~nm}$ can easily penetrate cells, and $\sim 40$ $\mathrm{nm}$ can enter nuclei, and below $35 \mathrm{~nm}$ can cross the blood-brain barrier (Ganguly et al., 2018; Malakar and Snow, 2020). Moreover, catalytic activity, the potential for producing ROS, adsorption rates, and binding capability can be enhanced in smaller NMs (Ning et al., 2017; Sajid et al., 2015) may influence residence times inside the body.

The fact that size is the most critical factor is evident in several studies carried out by Sahu and his colleagues on the genotoxicity and cytotoxicity of Ag NMs on human liver cells (Sahu et al., 2016a, 2016b, 2014). The studies observed toxic effects of Ag NMs varied according to size, where exposure to smaller NM led to a more potent impact (Sahu et al., 2016a, 2016b, 2014). Au NMs are extensively used in different medical applications but are known to impact embryonic stem cells in humans, mainly dependent on the size (Senut et al., 2016). Stem cells exposed to $1.5 \mathrm{~nm}$ gold NMs showed less cohesiveness and detachment indicative of cellular death, while larger NMs at $4 \mathrm{~nm}$ and $14 \mathrm{~nm}$ size did not display signs of toxicity (Senut et al., 2016). In Fig. 8, reproduced from the study by Senut et al. (2016), the toxic effects of gold nanoparticles 


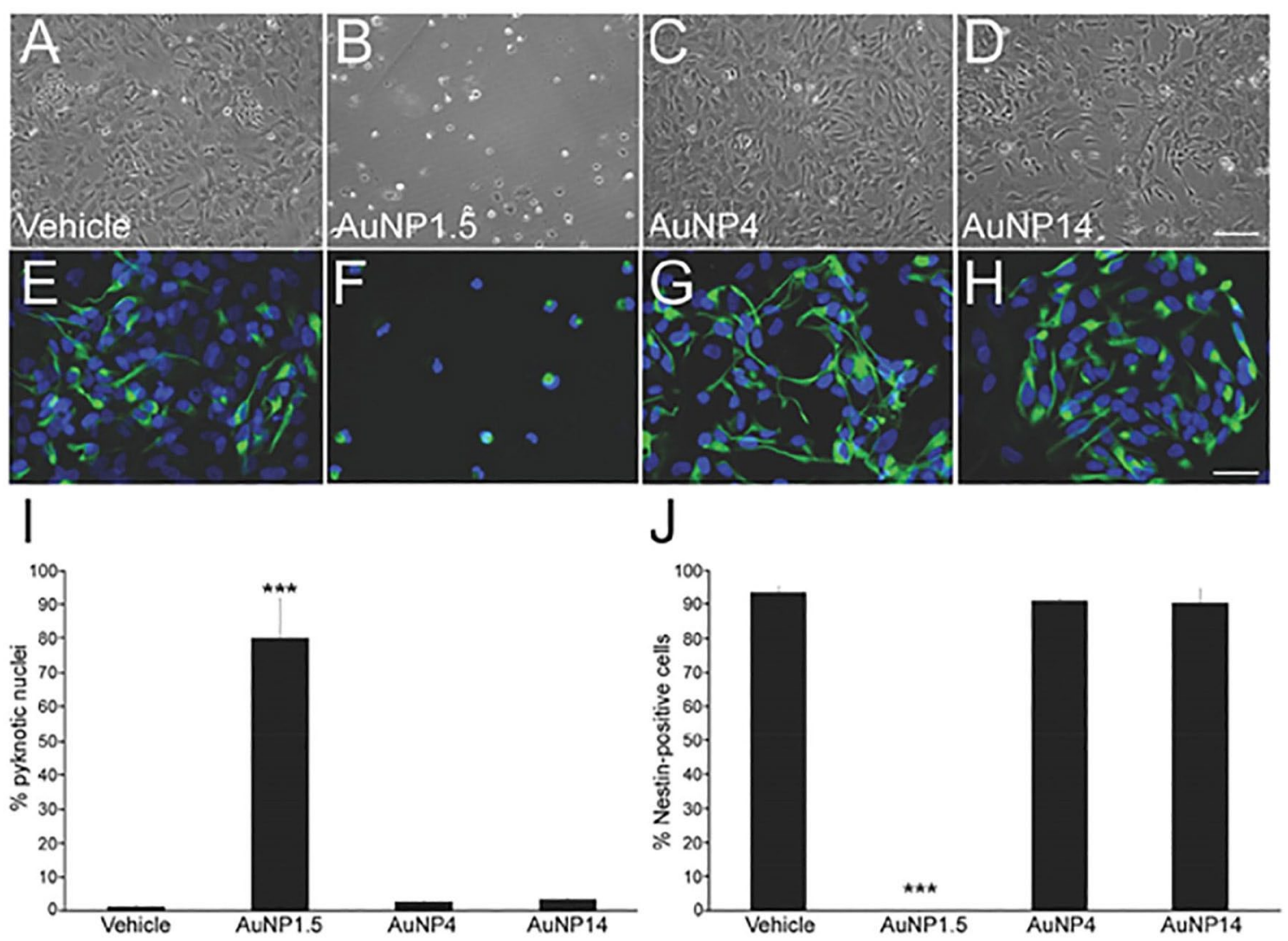

Fig. 8. The effects of AuNP on the survival of hESC-derived NPCs. NPCs were treated with vehicle or $10 \mu \mathrm{gml}^{-1}$ of AuNP1.5, AuNP4, and AuNP14 for $72 \mathrm{~h}$, processed for immunofluorescence detection of Nestin, and then stained with the nuclear marker DAPI. hESC-derived NPCs exposed for $72 \mathrm{~h}$ to A, E) vehicle, B, F) AuNP1.5, C, G) AuNP4, and D, H) AuNP14. B, F)Whereas exposure to AuNP1.5 resulted in cell death, NPCs treated with C, G) AuNP4 and D, H) AuNP14 displayed a viability and a E-H) Nestin immunostaining similar to those observed in A, E) control conditions. I) Quantitative analysis of NPCs harboring pyknotic nuclei showed ongoing cell death in cells exposed to $10 \mu \mathrm{g} \mathrm{ml}^{-1}$ AuNP1.5. J) No Nestin-positive NPCs survived following $72 \mathrm{~h}$ exposure to AuNP1.5. Histogram values are means \pm SEM. Statistical significance compared to the vehicle control group is designated as $\left(^{* * *}\right)(\mathrm{p}<0.001 ; \mathrm{n}=3$, one-way ANOVA). The scale bar length is $100 \mu \mathrm{m}$ for (A)-(D) and $30 \mu \mathrm{m}$ for (E)-(H), reproduced from Senut et al. (2016) with permission from John Wiley \& Sons, Inc.

was found to differ based on sizes $(A, H)$ control or vehicle; $(B, F) 1.5 \mathrm{~nm}$ (AuNP1.5); (C, G) 4 nm (AuNP4); and (D, H) 14 nm (AuNP14) observed at $10 \mu \mathrm{g} \mathrm{ml}$ concentration. When exposed to $1.5 \mathrm{~nm}$ sized gold particles, cell death is marked from (I) the quantitative analysis of percentage 
pyknotic nuclei with a significant 54-fold increase $(\mathrm{p}=0.02)$ and lack of Nestin-positive neural precursor cells (NPCs) (J) in comparison, 4 and 14 nm showed viability.

$\mathrm{TiO}_{2}$ and silicon dioxide $\left(\mathrm{SiO}_{2}\right) \mathrm{NMs}$ can cause cytotoxicity to various cells such as telomerase-immortalized bronchiolar epithelial cells, 3T3 fibroblasts, and RAW 264.7 macrophages (Baranowska-Wójcik et al., 2020). Generalizing the size ranges of various NMs to promote toxicity is much complex as presently, there are no standardized toxicity procedures among scientists to compare different results. However, scientists have a common consensus that toxicity will generally increase in smaller size NMs and is the primary factor promoting toxicity.

The shape of NMs can also be a deciding factor regarding the effects on human health. Fibroblast cells presented higher toxicity to gold nanospheres $(\sim 61.46 \mathrm{~nm})$ than to nanostars $(\sim 33.69 \mathrm{~nm})$ of smaller diameter (Favi et al., 2015). Further, the smaller nanospheres were fatal at concentrations of $40 \mu \mathrm{g} \mathrm{ml}$, and nanostars at $400 \mu \mathrm{g} \mathrm{ml}^{-1}$ (Favi et al., 2015). However, another study by Steckiewicz et al., between gold nanorods ( $\sim 39 \mathrm{~nm}$ lengths, $18 \mathrm{~nm}$ width), nanospheres $(\sim 6.3 \mathrm{~nm})$, and nanostars $(\sim 215 \mathrm{~nm})$ found gold nanostars to be most toxic against human fetal osteoblast (hFOB 1.19), osteosarcoma (143B, MG63) and pancreatic duct cell (hTERT-HPNE) (Fig. 9) (Steckiewicz et al., 2019). These observations are clearly shown in Fig. 9, reproduced from Steckiewicz et al. (2019), which shows MTT (a (hFOB1.19 cells), b (MG63), and c (143B cells)), and NR assay (d (hF0B1.19 cells), e (MG-63), and $\mathrm{f}$ (143B cells)) cell viability based on morphology (nanorods, nanostars, and nanospheres) of different gold nanomaterials at various concentrations ( 0 (control), 0.3, 0.6, 1.2, 2.5, and $5 \mu \mathrm{g} \mathrm{ml}^{-1}$ ). In MTT assay, nanostars presented significantly decreased cell viability for all three cell types, but NR assay did not find much difference between the morphologies, especially at lower concentrations (Steckiewicz et al., 2019). $\mathrm{TiO}_{2}$ nanofilaments and nanorods can show significant cytotoxicity towards epithelial cells (Michalkova et al., 2020; Pavlovic et al., 2015). The crystal structure of NMs can affect their toxicity. For example, $\mathrm{TiO}_{2} \mathrm{NMs}$ of rutile structure showed more toxicity compared to anatase form (De Matteis, 2017; De Matteis and Rinaldi, 2018). Further, the crystal structure of NMs can change in environmental matrices (Mejia et al., 2016), which can make toxicity studies even more complicated. 


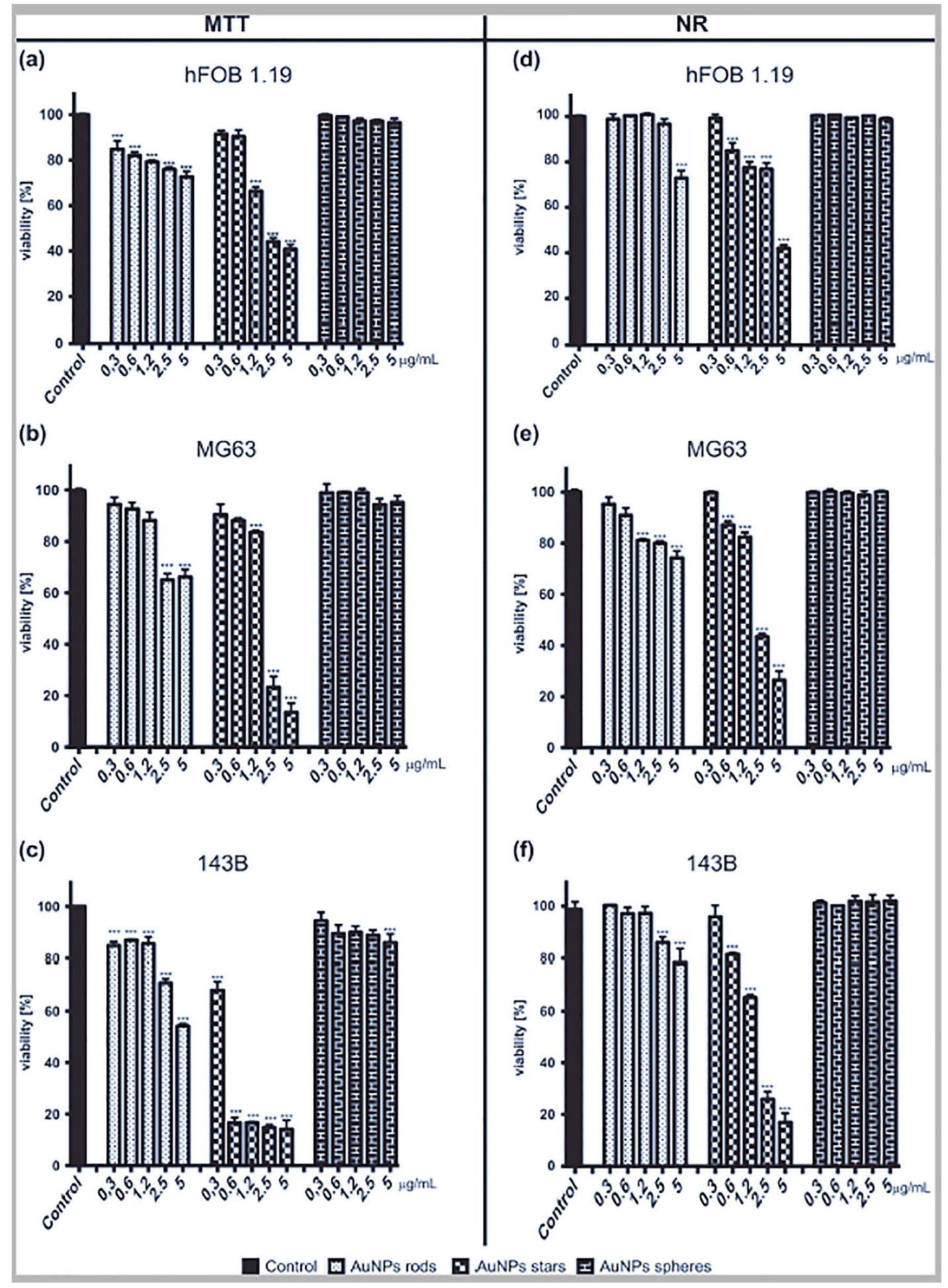

Fig. 9. Different shapes of AuNPs decreased cell viability in a concentration-dependent manner. Viability, measured by MTT test, of a hF0B1.19 cells, b MG-63, c 143B cells exposed to different shapes of AuNPs after $24 \mathrm{~h}$. Viability, measured by NR test, of d hFOB1.19 cells, e MG-63, f 143B cells exposed to different shapes of AuNPs after 24 h. Data are presented as mean \pm SD. ${ }^{*} \mathrm{p}<0.05,{ }^{* *} \mathrm{p}<0.01,{ }^{* * *} \mathrm{p}<0.001$ reproduced from Steckiewicz et al. (2019), with permission from Springer. 
Organic and inorganic moieties are utilized to functionalize ENMs for different applications provide a surface charge to NMs (Sajid et al., 2015). The surface chemistry of ENMs, can dictate their interaction in complex biological matrices and can be modified to decrease toxicity and enhance functionality. Organic capping agents in Ag ENMs were found to control the toxicity, fate, and stability of those ENMs (Sarma et al., 2015). Generally, ENMs with a positive surface charge can quickly enter cells due to electrostatic attraction leading to a prolonged retention time in the human body. ENMs can also bring about conformational changes in the bound protein and affect their functional activities and cause disease (e.g., amyloidosis) (Sukhanova et al., 2018, 2012). The surface charge change can modify other characteristics like aggregation and hydrodynamic diameter. Changes in the surface property can affect how NMs interact with cells, tissue, and organs, regulating their uptake and adsorption (Allouni et al., 2015). The stability of ENMs inside the human body can increase the residence time of NMs and can also increase the toxic effect by delayed excretion (Gupta and Xie, 2018).

Various mitigating measures should be considered to ensure that ENMs do not occur at hazardous levels in soil, air, and water. Particulate based air pollution is a serious concern to human health, and filtration units can be utilized at the disposal points to minimize the introduction of incidental NMs to the environment. Wastewater treatment facilities are primary points where synthetic NMs, are discharged to the environment. Treatment facilities can be modified to ensure proper removal of NMs before discharge to the environment. Monitoring of treated wastewater can provide important insight into the presence of NMs in the final water (Malakar and Snow, 2020). Human health impacts should not be limited to ENMs, and exposure from natural NMs should also be considered. The crucial effect of ubiquitous NNMs on organ functions needs additional studies. Air purifiers and proper filtration of water can minimize intake by respiratory and ingestion pathways. Newly developed commercial NMs should pass through stringent testing to assess their potential toxicity and fate in the complex natural environment. A thorough life-cycle analysis of various NMs can be used to help devise plans to mitigate the negative impacts of NMs on both environmental safety and human health. 


\section{Conclusions}

The understanding of the life cycle of natural and synthetic NMs demands critical attention. The underlying biogeochemical impacts on different natural resources due to NMs need to be grasped to devise plans to protect the environment, especially those which have consequences to human health. The widespread occurrence of nanomaterials in the water supplies, air, and soils used for food crops is evident and concerning. The nanoscale size of NMs is a critical factor that impedes the understanding of NMs fate in the environment. As more NMs, specifically ENMs, are introduced to the environment, their potential toxicity needs to be better understood to predict long term consequences. Proactive measures may prevent nanomaterials entry to the environment and minimize their effects to the ecosystem and human health. The toxicological implications of the occurrence and exposure of natural, incidental, and engineered NMs are far from clear. Present-day analytical techniques are not sophisticated enough to study NMs in the complex natural environment and biological systems. Recent scientific efforts have contributed to a better understanding of the interaction of NMs with cell, tissue, and organs. As with any group of hazardous contaminants, multiple exposure pathways should be considered, and more research is needed to evaluate human health effects from the occurrence of NMs in the environment.

\section{Future perspective}

The focus on intricate role NMs, both natural and engineered, needs critical attention soon. Natural NMs role in controlling major cycles such as carbon, nitrogen, and phosphorus in the natural environment is being considered in the present research, and continued scientific efforts are needed to realize NNMs real impact on biogeochemical cycles. Future research efforts should be towards developing easy, cost-effective, and highly reproducible analytical tools to understand the role of NMs in the various environmental matrix. Understanding the different ways NMs interact and influence abiotic and biotic ecosystems will help establish ground rules on their potential impact on the environment and help formulate plans to mitigate the transmission to humans. There is a 
severe lack of research on the effects of natural NMs on human health, and future nanotoxicity studies should rigorously look into natural NMs effect on different humans.

Competing interest The authors declare that they have no known competing financial interests or personal relationships that could have appeared to influence the work reported in this paper.

Acknowledgments This work is based on research that was partially supported by the Nebraska Agricultural Experiment Station with funding from the Hatch Multistate Research (Accession Number 1011588) through the USDA National Institute of Food and Agriculture.

\section{References}

Adegboyega, N.F., Sharma, V.K., Cizmas, L., Sayes, C.M., 2016. UV light induces Ag nanoparticle formation: roles of natural organic matter, iron, and oxygen. Environ. Chem. Lett. 14, 353-357. https://doi.org/10.1007/s10311-016-0577-z

Alizadeh, S., Ghoshal, S., Comeau, Y., 2019. Fate and inhibitory effect of silver nanoparticles in high rate moving bed biofilm reactors. Sci. Total Environ. 647, 1199-1210. https://doi.org/10.1016/j.scitotenv.2018.08.073

Allouni, Z.E., Gjerdet, N.R., Cimpan,M.R., Høl, P.J., 2015. The effect of blood protein adsorption on cellular uptake of anatase TiO2 nanoparticles. Int. J. Nanomedicine 10, 687-695. https://doi.org/10.2147/IJN.S72726

Arvidsson, R., Baun, A., Furberg, A., Hansen, S.F., Molander, S., 2018. Proxy measures for simplified environmental assessment of manufactured nanomaterials. Environ. Sci. Technol. 52, 13670-13680. https://doi.org/10.1021/acs. est.8b05405

Baalousha, M., Yang, Y., Vance,M.E., Colman, B.P., McNeal, S., Xu, J., Blaszczak, J., Steele, M., Bernhardt, E., Hochella, M.F., 2016. Outdoor urban nanomaterials: the emergence of a new, integrated, and critical field of study. Sci. Total Environ. 557558, 740-753. https://doi.org/10.1016/j.scitotenv.2016.03.132

Baalousha, M., Stoll, S., Motelica-Heino, M., Guigues, N., Braibant, G., Huneau, F., Le Coustumer, P., 2019. Suspended particulate matter determines physical speciation of Fe, Mn, and trace metals in surface waters of Loire watershed. Environ. Sci. Pollut. Res. 26, 5251-5266. https://doi.org/10.1007/s11356-018-1416-5

Banfield, J.F., Zhang, H., 2001. Nanoparticles in the environment. Rev. Mineral. Geochem. 44, 1-58. https://doi.org/10.2138/rmg.2001.44.01

Baranowska-Wójcik, E., Szwajgier, D., Oleszczuk, P., Winiarska-Mieczan, A., 2020. Effects of titanium dioxide nanoparticles exposure on human health-a review. Biol. Trace Elem. Res. 193, 118-129. https://doi.org/10.1007/ s12011-019-01706-6 
Bardos, P., Merly, C., Kvapil, P., Koschitzky, H.P., 2018. Status of nanoremediation and its potential for future deployment: risk-benefit and benchmarking appraisals. Remediation 28, 43-56. https://doi.org/10.1002/rem.21559

Barton, L.E., Auffan, M., Durenkamp, M., McGrath, S., Bottero, J.Y., Wiesner, M.R., 2015. Monte Carlo simulations of the transformation and removal of Ag, TiO2, and $\mathrm{ZnO}$ nanoparticles in wastewater treatment and land application of biosolids. Sci. Total Environ. 511, 535-543. https://doi.org/10.1016/i.scitotenv.2014.12.056

Basei, G., Hristozov, D., Lamon, L., Zabeo, A., Jeliazkova, N., Tsiliki, G., Marcomini, A., Torsello, A., 2019. Making use of available and emerging data to predict the hazards of engineered nanomaterials bymeans of in silico tools: a critical review. NanoImpact 13, 76-99. https://doi.org/10.1016/j.impact.2019.01.003

Basinas, I., Jiménez, A.S., Galea, K.S., Tongeren, M. van, Hurley, F., 2018. A systematic review of the routes and forms of exposure to engineered nanomaterials. Ann. Work Expo. Heal. 62, 639-662. https://doi.org/10.1093/annweh/wxy048

Bäuerlein, P.S., Emke, E., Tromp, P., Hofman, J.A.M.H., Carboni, A., Schooneman, F., de Voogt, P., van Wezel, A.P., 2017. Is there evidence for man-made nanoparticles in the Dutch environment? Sci. Total Environ. 576, 273-283. https://doi. org/10.1016/j.scitotenv.2016.09.206

Baun, A., Sayre, P., Steinhäuser, K.G., Rose, J., 2017. Regulatory relevant and reliable methods and data for determining the environmental fate of manufactured nanomaterials. NanoImpact 8, 1-10. https://doi.org/10.1016/j. impact.2017.06.004

Belal, E.-S., El-Ramady, H., 2016. Nanoparticles in water, soils and agriculture. In: Ranjan, S., Dasgupta, N., Lichtfouse, E. (Eds.), Nanoscience in Food and Agriculture 2, Sustainable Agriculture Reviews. Springer, 233 Spring Street, New York, Ny 10013, United States, pp. 311-358 https://doi. org/10.1007/978-3-319-39306-3 10

Besseling, E., Redondo-Hasselerharm, P., Foekema, E.M., Koelmans, A.A., 2019. Quantifying ecological risks of aquatic micro- and nanoplastic. Crit. Rev. Environ. Sci. Technol. 49, 32-80. https://doi.org/10.1080/10643389.2018.1531688

Boncel, S., Kyziol-Komosińska, J., Krzyzewska, I., Czupiol, J., 2015. Interactions of carbon nanotubes with aqueous/aquatic media containing organic/ inorganic contaminants and selected organisms of aquatic ecosystems - a review. Chemosphere 136, 211-221. https://doi.org/10.1016/j. chemosphere.2015.04.095

Bour, A., Mouchet, F., Silvestre, J., Gauthier, L., Pinelli, E., 2015. Environmentally relevant approaches to assess nanoparticles ecotoxicity: a review. J. Hazard. Mater. 283, 764-777. https://doi.org/10.1016/i.jhazmat.2014.10.021

Boyes, W.K., van Thriel, C., 2020. Neurotoxicology of nanomaterials. Chem. Res. Toxicol. 33, 1121-1144. https://doi.org/10.1021/acs.chemrestox.0c00050 Brown, K., Thurn, T., Xin, L., Liu, W., Bazak, R., Chen, S., Lai, B., Vogt, S., Jacobsen, C., Paunesku, T.,Woloschak, G.E., 2018. Intracellular in situ labeling of TiO2 nanoparticles for fluorescence microscopy detection. Nano Res. 11, 464-476. https://doi.org/10.1007/s12274-017-1654-8 
Bundschuh, M., Filser, J., Lüderwald, S., McKee, M.S., Metreveli, G., Schaumann, G.E., Schulz, R., Wagner, S., 2018. Nanoparticles in the environment: where do we come from, where do we go to? Environ. Sci. Eur. 30, 6. https://doi.org/10.1186/ $\underline{\text { s12302-018-0132-6 }}$

Cai, J., Zang, X., Wu, Z., Liu, J., Wang, D., 2019. Translocation of transition metal oxide nanoparticles to breast milk and offspring: the necessity of bridging motheroffspring- integration toxicological assessments. Environ. Int. 133, 105153. https://doi.org/10.1016/j.envint.2019.105153

Chen, L., Li, J., Chen, Z., Gu, Z., Yan, L., Zhao, F., Zhang, A., 2019. Toxicological evaluation of graphene-family nanomaterials. J. Nanosci. Nanotechnol. 20, 19932006. https://doi.org/10.1166/inn.2020.17364

Choi, S., Johnston, M.V., Wang, G.S., Huang, C.P., 2017. Looking for engineered nanoparticles (ENPs) in wastewater treatment systems: qualification and quantification aspects. Sci. Total Environ. 590-591, 809-817. https://doi. org/10.1016/j.scitotenv.2017.03.061

Christou, A., Stec, A.A., Ahmed,W., Aschberger, K., Amenta, V., 2016. A review of exposure and toxicological aspects of carbon nanotubes, and as additives to fire retardants in polymers. Crit. Rev. Toxicol. https://doi.org/10.3109/10408444.20 15.1082972

Coman, V., Oprea, I., Leopold, L.F., Vodnar, D.C., Coman, C., 2019. Soybean interaction with engineered nanomaterials: a literature review of recent data. Nanomaterials 9, 1248. https://doi.org/10.3390/nano9091248

Courty, M.-A., Martinez, J.-M., 2015. Terrestrial carbonaceous debris tracing atmospheric hypervelocity-shock aeroplasma processes. Proc. Eng. 103, 81-88. https://doi.org/10.1016/j.proeng.2015.04.012

Courty, M.-A., Allue, E., Henry, A., 2020. Forming mechanisms of vitrified charcoals in archaeological firing-assemblages. J. Archaeol. Sci. Rep. 30, 102215. https://doi. org/10.1016/j.jasrep.2020.102215

Crampon, M., Joulian, C., Ollivier, P., Charron, M., Hellal, J., 2019. Shift in natural groundwater bacterial community structure due to zero-valent iron nanoparticles (nZVI). Front. Microbiol. 10. https://doi.org/10.3389/fmicb.2019.00533

Cronin, J.G., Jones, N., Thornton, C.A., Jenkins, G.J.S., Doak, S.H., Clift, M.J.D., 2020. Nanomaterials and innate immunity: a perspective of the current status in nanosafety. Chem. Res. Toxicol. 33, 1061-1073. https://doi.org/10.1021/acs. chemrestox.0c00051

Das, R.K., Pachapur, V.L., Lonappan, L., Naghdi, M., Pulicharla, R., Maiti, S., Cledon, M., Dalila, L.M.A., Sarma, S.J., Brar, S.K., 2017. Biological synthesis of metallic nanoparticles: plants, animals and microbial aspects. Nanotechnol. Environ. Eng. 2, 18. https://doi.org/10.1007/s41204-017-0029-4

De Matteis, V., 2017. Exposure to inorganic nanoparticles: routes of entry, immune response, biodistribution and in vitro/in vivo toxicity evaluation. Toxics 5, 29. https://doi.org/10.3390/toxics5040029

De Matteis, V., Rinaldi, R., 2018. Toxicity assessment in the nanoparticle era. Advances in Experimental Medicine and Biology. Springer, Cham, pp. 1-19 https://doi.org/10.1007/978-3-319-72041-8 1 
Ding, G., Zhang, N.,Wang, C., Li, X., Zhang, J., Li,W., Li, R., Yang, Z., 2018. Effect of the size on the aggregation and sedimentation of graphene oxide in seawaters with different salinities. J. Nanopart. Res. 20, 313. https://doi.org/10.1007/ s11051-018-4421-1

Durenkamp, M., Pawlett, M., Ritz, K., Harris, J.A., Neal, A.L., McGrath, S.P., 2016. Nanoparticles withinWWTP sludges haveminimal impact on leachate quality and soilmicrobial community structure and function. Environ. Pollut. 211, 399-405. https://doi.org/10.1016/j.envpol.2015.12.063

Eivazzadeh-Keihan, R., Maleki, A., de la Guardia, M., Bani, M.S., Chenab, K.K., Pashazadeh- Panahi, P., Baradaran, B., Mokhtarzadeh, A., Hamblin, M.R., 2019. Carbon based nanomaterials for tissue engineering of bone: building new bone on small black scaffolds: a review. J. Adv. Res. 18, 185-201. https://doi. org/10.1016/j.jare.2019.03.011

Erbs, J.J., Berquó, T.S., Reinsch, B.C., Lowry, G.V., Banerjee, S.K., Penn, R.L., 2010. Reductive dissolution of arsenic-bearing ferrihydrite. Geochim. Cosmochim. Acta 74, 3382-3395. https://doi.org/10.1016/i.gca.2010.01.033

Ermolin, M.S., Fedotov, P.S., 2016. Separation and characterization of environmental nano- and submicron particles. Rev. Anal. Chem. 35 (4), 185-199. https://doi. org/10.1515/revac-2016-0006

Ermolin, M.S., Fedotov, P.S.,Malik, N.A., Karandashev, V.K., 2018. Nanoparticles of volcanic ash as a carrier for toxic elements on the global scale. Chemosphere 200, 16-22. https://doi.org/10.1016/j.chemosphere.2018.02.089

Fang, Q., Chen, B., 2012. Adsorption of perchlorate onto raw and oxidized carbon nanotubes in aqueous solution. Carbon 50 (6), 2209-2219. https://doi. org/10.1016/j.carbon.2012.01.036

Fang, Q., Shen, Y., Chen, B., 2015. Synthesis, decoration and properties of threedimensional graphene-based macrostructures: a review. Chem. Eng. J. 264, 753-771. https://doi.org/10.1016/j.cej.2014.12.001

Faulstich, L., Griffin, S., Nasim, M.J., Masood, M.I., Ali, W., Alhamound, S., Omran, Y., Kim, H., Kharma, A., Schäfer, K.H., Lilischkis, R.,Montenarh, M., Keck, C., Jacob, C., 2017. Nature's hat-trick: can we use sulfur springs as ecological source for materials with agricultural and medical applications? Int. Biodeterior. Biodegrad. 119, 678-686. https://doi.org/10.1016/j.ibiod.2016.08.020

Favi, P.M., Gao, M., Johana Sepúlveda Arango, L., Ospina, S.P., Morales, M., Pavon, J.J., Webster, T.J., 2015. Shape and surface effects on the cytotoxicity of nanoparticles: gold nanospheres versus gold nanostars. J. Biomed. Mater. Res. A 103, 34493462. https://doi.org/10.1002/ibm.a.35491

Gad, G.M.A., Hegazy, M.A., 2019. Optoelectronic properties of gold nanoparticles synthesized by using wet chemical method. Mater. Res. Express 6, 085024. https://doi.org/10.1088/2053-1591/ab1bb8

Ganguly, P., Breen, A., Pillai, S.C., 2018. Toxicity of nanomaterials: exposure, pathways, assessment, and recent advances. ACS Biomater. Sci. Eng. 4, 22372275. https://doi.org/10.1021/acsbiomaterials.8b00068

Gao, Y., Jing, H., Du, M., Chents, W., 2018. Dispersion of multi-walled carbon nanotubes stabilized by humic acid in sustainable cement composites. Nanomaterials 8, 858. https://doi.org/10.3390/nano8100858 
Geiser, M., Jeannet, N., Fierz, M., Burtscher, H., 2017. Evaluating adverse effects of inhaled nanoparticles by realistic in vitro technology. Nanomaterials 7, 49. https://doi.org/10.3390/nano7020049

Ghosh, S., Pradhan, N.R., Mashayekhi, H., Zhang, Q., Pan, B., Xing, B., 2016. Colloidal aggregation and structural assembly of aspect ratio variant goethite $(\alpha-\mathrm{FeOOH})$ with nC60 fullerene in environmental media. Environ. Pollut. 219, 1049-1059. https://doi.org/10.1016/i.envpol.2016.09.005

Ghoshdastidar, A.J., Ariya, P.A., 2019. The existence of airbornemercury nanoparticles. Sci. Rep. 9, 10733. https://doi.org/10.1038/s41598-019-47086-8

Gogos, A.,Wielinski, J., Voegelin, A., Emerich, H., Kaegi, R., 2019. Transformation of cerium dioxide nanoparticles during sewage sludge incineration. Environ. Sci. Nano 6, 1765-1776. https://doi.org/10.1039/c9en00281b

González-Gálvez, D., Janer, G., Vilar, G., Vílchez, A., Vázquez-Campos, S., 2017. The life cycle of engineered nanoparticles. Advances in Experimental Medicine and Biology. Springer, Cham, pp. 41-69 https://doi. org/10.1007/978-3-319-47754-1 3

Good, K.D., Bergman, L.E., Klara, S.S., Leitch, M.E., VanBriesen, J.M., 2016. Implications of engineered nanomaterials in drinking water sources. J. Am. Water Works Assoc. 108, E1-E17. https://doi.org/10.5942/jawwa.2016.108.0013

Goswami, L., Kim, K.H., Deep, A., Das, P., Bhattacharya, S.S., Kumar, S., Adelodun, A.A., 2017. Engineered nano particles: nature, behavior, and effect on the environment. J. Environ. Manag. 196, 297-315. https://doi.org/10.1016/j.jenvman.2017.01.011 Griffin, S., Masood, M.I., Nasim, M.J., Sarfraz, M., Ebokaiwe, A.P., Schäfer, K.H., Keck, C.M., Jacob, C., 2018. Natural nanoparticles: a particular matter inspired by nature. Antioxidants 7, 3. https://doi.org/10.3390/antiox7010003

Grillo, R., Rosa, A.H., Fraceto, L.F., 2015. Engineered nanoparticles and organicmatter: a review of the state-of-the-art. Chemosphere 119, 608-619. https://doi.org/10.1016/j.chemosphere.2014.07.049

Gupta, R., Xie, H., 2018. Nanoparticles in daily life: applications, toxicity and regulations. J. Environ. Pathol. Toxicol. Oncol. 37, 209-230. https://doi. org/10.1615/JEnvironPatholToxicolOncol.2018026009

Han, J., Zhao, D., Li, D., Wang, X., Jin, Z., Zhao, K., 2018. Polymer-based nanomaterials and applications for vaccines and drugs. Polymers (Basel) 10, 31. https://doi. org/10.3390/polym 10010031

Hartland, A., Lead, J.R., Slaveykova, V.I., 2013. The environmental significance of natural nanoparticles. Nat. Educ. Knowl. 4, 7.

Hashem, N.M., Gonzalez-Bulnes, A., 2020. State-of-the-art and prospective of nanotechnologies for smart reproductive management of farm animals. Animals 10, 840. https://doi.org/10.3390/ani10050840

Hashem, N.M., Sallam, S.M., 2020. Reproductive performance of goats treated with free gonadorelin or nanoconjugated gonadorelin at estrus. Domest. Anim. Endocrinol. 71, 106390. https://doi.org/10.1016/j.domaniend.2019.106390

Hauser, M., Li, G., Nowack, B., 2019. Environmental hazard assessment for polymeric and inorganic nanobiomaterials used in drug delivery. J. Nanobiotechnol. 17, 56. https://doi.org/10.1186/s12951-019-0489-8 
He, C.S., He, P.P., Yang, H.Y., Li, L.L., Lin, Y.,Mu, Y., Yu, H.Q., 2017. Impact of zero-valent iron nanoparticles on the activity of anaerobic granular sludge: from macroscopic to microcosmic investigation. Water Res. 127, 32-40. https://doi.org/10.1016/j. watres.2017.09.061

Hochella, M.F., 2008. Nanogeoscience: from origin to cutting-edge applications. Elements 4, 373-379. https://doi.org/10.2113/gselements.4.6.373

Hochella, M.F., Spencer, M.G., Jones, K.L., 2015. Nanotechnology: nature's gift or scientists' brainchild? Environ. Sci. Nano 2, 114-119. https://doi.org/10.1039/ c4en00145a

Hochella, M.F., Mogk, D.W., Ranville, J., Allen, I.C., Luther, G.W., Marr, L.C., McGrail, B.P., Murayama, M., Qafoku, N.P., Rosso, K.M., Sahai, N., Schroeder, P.A., Vikesland, P., Westerhoff, P., Yang, Y., 2019. Natural, incidental, and engineered nanomaterials and their impacts on the earth system. Science 363 (6434). https://doi. org/10.1126/science.aau8299

Hoggan, J.L., Sabatini, D.A., Kibbey, T.C.G., 2016. Transport and retention of TiO2 and polystyrene nanoparticles during drainage from tall heterogeneous layered columns. J. Contam. Hydrol. 194, 30-35. https://doi.org/10.1016/j. jconhyd.2016.10.003

Huang, Y.W., Cambre, M., Lee, H.J., 2017. The toxicity of nanoparticles depends on multiple molecular and physicochemical mechanisms. Int. J. Mol. Sci. 18, 2702. https://doi.org/10.3390/ijms18122702

Iavicoli, I., Leso, V., Beezhold, D.H., Shvedova, A.A., 2017. Nanotechnology in agriculture: opportunities, toxicological implications, and occupational risks. Toxicol. Appl. Pharmacol. 329, 96-111. https://doi.org/10.1016/j. taap.2017.05.025

Inshakova, E., Inshakov, O., 2017. World market for nanomaterials: structure and trends. MATEC Web Conf. 129, 02013. https://doi.org/10.1051/ matecconf/201712902013

Jain, R., Jordan, N., Tsushima, S., Hübner, R., Weiss, S., Lens, P.N.L., 2017. Shape change of biogenic elemental seleniumnanomaterials fromnanospheres to nanorods decreases their colloidal stability. Environ. Sci. Nano 4, 1054-1063. https://doi. org/10.1039/c7en00145b

Jawed, A., Saxena, V., Pandey, L.M., 2020. Engineered nanomaterials and their surface functionalization for the removal of heavy metals: a review. J. Water Process Eng. 33, 101009. https://doi.org/10.1016/j.jwpe.2019.101009

Jeevanandam, J., Barhoum, A., Chan, Y.S., Dufresne, A., Danquah, M.K., 2018. Review on nanoparticles and nanostructured materials: history, sources, toxicity and regulations. Beilstein J. Nanotechnol. 9, 1050-1074. https://doi.org/10.3762/ bjnano.9.98

Jesus, S., Schmutz, M., Som, C., Borchard, G.,Wick, P., Borges, O., 2019. Hazard assessment of polymeric nanobiomaterials for drug delivery: what can we learn from literature so far. Front. Bioeng. Biotechnol. 7, 261. https://doi.org/10.3389/ fbioe.2019.00261

Jiang, D., Zeng, G., Huang, D., Chen, M., Zhang, C., Huang, C.,Wan, J., 2018. Remediation of contaminated soils by enhanced nanoscale zero valent iron. Environ. Res. 163, 217-227. https://doi.org/10.1016/j.envres.2018.01.030 
Jiang, L.,Wang, Y., Liu, Z., Ma, C., Yan, H., Xu, N., Gang, F.,Wang, X., Zhao, L., Sun, X., 2019. Three-dimensional printing and injectable conductive hydrogels for tissue engineering application. Tissue Eng. B Rev. 25, 398-411. https://doi. org/10.1089/ten.teb.2019.0100

Joshi, N., Filip, J., Coker, V.S., Sadhukhan, J., Safarik, I., Bagshaw, H., Lloyd, J.R., 2018.Microbial reduction of natural Fe(III) minerals; toward the sustainable production of functional magnetic nanoparticles. Front. Environ. Sci. 6, 127. https://doi.org/10.3389/fenvs.2018.00127

Kaegi, R., Voegelin, A., Sinnet, B., Zuleeg, S., Siegrist, H., Burkhardt, M., 2015. Transformation of AgCl nanoparticles in a sewer system - a field study. Sci. Total Environ. 535, 20-27. https://doi.org/10.1016/i.scitotenv.2014.12.075

Kah, M., Kookana, R.S., Gogos, A., Bucheli, T.D., 2018. A critical evaluation of nanopesticides and nanofertilizers against their conventional analogues. Nat. Nanotechnol. 13, 677-684. https://doi.org/10.1038/s41565-018-0131-1

Kanel, S.R., Al-Abed, S.R., 2011. Influence of $\mathrm{pH}$ on the transport of nanoscale zinc oxide in saturated porous media. J. Nanopart. Res. 13, 4035-4047. https://doi. org/10.1007/s11051-011-0345-8

Kanel, S.R., Choi, H., 2007. Transport characteristics of surface-modified nanoscale zerovalent iron in porous media. Water Sci. Technol. 55, 157-162. https://doi. org/10.2166/wst.2007.002

Kanel, S.R., Choi, H., Kim, J.Y., Vigneswaran, S., Shim, W.G., 2006a. Removal of arsenic(III) from groundwater using low-cost industrial by-products - blast furnace slag. Water Qual. Res. J. Can. 41, 130-139. https://doi.org/10.2166/ wqrj.2006.015

Kanel, S.R., Greneche, J.M., Choi, H., 2006b. Arsenic(V) removal from groundwater using nano scale zero-valent iron as a colloidal reactive barrier material. Environ. Sci. Technol. 40, 2045-2050. https://doi.org/10.1021/es0520924

Kanel, S.R., Goswami, R.R., Clement, T.P., Barnett, M.O., Zhao, D., 2008. Two dimensional transport characteristics of surface stabilized zero-valent iron nanoparticles in porous media. Environ. Sci. Technol. 42, 896-900. https://doi. org/10.1021/es071774j

Kanel, S.R., Misak, H., Nepal, D., Mall, S., Brittle, S.W., Sizemore, I., Kempisty, D.M., Goltz, M.N., 2016. The use of carbon nanotube yarn as a filter medium to treat nitroaromatic-contaminated water. Xinxing Tan Cailiao/New Carbon Mater. 31, 415-423. https://doi.org/10.1016/S1872-5805(16)60021-5

Khan, Ibrahim, Saeed, K., Khan, Idrees, 2019. Nanoparticles: properties, applications and toxicities. Arab. J. Chem. 12, 908-931. https://doi.org/10.1016/j. arabjc.2017.05.011

Kirkegaard, P., Hansen, S.F., Rygaard, M., 2015. Potential exposure and treatment efficiency of nanoparticles in water supplies based on wastewater reclamation. Environ. Sci. Nano 2, 191-202. https://doi.org/10.1039/c4en00192c

Koelmans, A.A., Diepens, N.J., Velzeboer, I., Besseling, E., Quik, J.T.K., van de Meent, D., 2015a. Guidance for the prognostic risk assessment of nanomaterials in aquatic ecosystems. Sci. Total Environ. 535, 141-149. https://doi.org/10.1016/j. $\underline{\text { scitotenv.2015.02.032 }}$ 
Koelmans, A.A., Quik, J.T.K., Velzeboer, I., 2015b. Lake retention ofmanufactured nanoparticles. Environ. Pollut. 196, 171-175. https://doi.org/10.1016/j. envpol.2014.09.025

Korin, N., Kanapathipillai, M., Ingber, D.E., 2013. Shear-responsive platelet mimetics for targeted drug delivery. Isr. J. Chem. 53, 610-615. https://doi.org/10.1002/ ijch.201300052

Kretzschmar, R., Sticher, H., 1998. Colloid transport in natural porous media: influence of surface chemistry and flow velocity. Phys. Chem. Earth 23, 133-139. https://doi.org/10.1016/S0079-1946(98)00003-2

Kunhikrishnan, A., Shon, H.K., Bolan, N.S., El Saliby, I., Vigneswaran, S., 2015. Sources, distribution, environmental fate, and ecological effects of nanomaterials in wastewater streams. Crit. Rev. Environ. Sci. Technol. 45, 277-318. https://doi.org $\not 10.1080 / 10643389.2013 .852407$

Laborda, F., Bolea, E., Cepriá, G., Gómez, M.T., Jiménez, M.S., Pérez-Arantegui, J., Castillo, J.R., 2016. Detection, characterization and quantification of inorganic engineered nanomaterials: a review of techniques and methodological approaches for the analysis of complex samples. Anal. Chim. Acta 904, 10-32. https://doi.org/10.1016/j.aca.2015.11.008

Larese Filon, F., Mauro, M., Adami, G., Bovenzi, M., Crosera, M., 2015. Nanoparticles skin absorption: new aspects for a safety profile evaluation. Regul. Toxicol. Pharmacol. 72, 310-322. https://doi.org/10.1016/i.yrtph.2015.05.005

Lawrence, J.R., Swerhone, G.D.W., Dynes, J.J., Hitchcock, A.P., Korber, D.R., 2016. Complex organic corona formation on carbon nanotubes reduces microbial toxicity by suppressing reactive oxygen species production. Environ. Sci. Nano 3, 181-189. https://doi.org/10.1039/c5en00229j

Lead, J.R., Batley, G.E., Alvarez, P.J.J., Croteau,M.N., Handy, R.D., McLaughlin, M.J., Judy, J.D., Schirmer, K., 2018. Nanomaterials in the environment: behavior, fate, bioavailability, and effects-an updated review. Environ. Toxicol. Chem. 37, 20292063. https://doi.org/10.1002/etc.4147

Lehner, R., Weder, C., Petri-Fink, A., Rothen-Rutishauser, B., 2019. Emergence of nanoplastic in the environment and possible impact on human health. Environ. Sci. Technol. 53, 1748-1765. https://doi.org/10.1021/acs.est.8b05512

Lei, C., Zhang, L., Yang, K., Zhu, L., Lin, D., 2016. Toxicity of iron-based nanoparticles to green algae: effects of particle size, crystal phase, oxidation state and environmental aging. Environ. Pollut. 218, 505-512. https://doi.org/10.1016/j. envpol.2016.07.030

Lewis, R.W., Bertsch, P.M., McNear, D.H., 2019. Nanotoxicity of engineered nanomaterials (ENMs) to environmentally relevant beneficial soil bacteria - a critical review. Nanotoxicology 13, 392-428. https://doi.org/10.1080/17435390 .2018 .1530391

Liu, J., Zhu, R., Xu, T., Laipan, M., Zhu, Y., Zhou, Q., Zhu, J., He, H., 2018. Interaction of polyhydroxy fullerenes with ferrihydrite: adsorption and aggregation. J. Environ. Sci. (China) 64, 1-9. https://doi.org/10.1016/i.jes.2017.06.016

Lowry, G.V., Gregory, K.B., Apte, S.C., Lead, J.R., 2012. Transformations of nanomaterials in the environment. Environ. Sci. Technol. 46 (13), 6893-6899. https://doi.org/10.1021/es300839e 
Lungu, M., Neculae, A., Bunoiu, M., Biris, C., 2015. Nanoparticles' Promises and Risks, Nanoparticles' Promises and Risks: Characterization, Manipulation, and Potential Hazards to Humanity and the Environment. Springer International Publishing, Cham https://doi.org/10.1007/978-3-319-11728-7

Luo, P., Roca, A., Tiede, K., Privett, K., Jiang, J., Pinkstone, J., Ma, G., Veinot, J., Boxall, A., 2018. Application of nanoparticle tracking analysis for characterising the fate of engineered nanoparticles in sediment-water systems. J. Environ. Sci. 64, 62-71. https://doi.org/10.1016/j.jes.2016.07.019

Ma, Z.,Yin,X., Ji,X., Yue, J.Q., Zhang, L., Qin, J.J.,Valiyaveettil, S., Adin,A., 2016. Evaluation and removal of emerging nanoparticle contaminants in water treatment: a review. Desalin. Water Treat. 57, 11221-11232. https://doi.org/10.1080/19443994.201 $\underline{5.1038734}$

Maher, B.A., Ahmed, I.A.M., Karloukovski, V.,MacLaren, D.A., Foulds, P.G., Allsop, D., Mann, D.M.A., Torres-Jardón, R., Calderon-Garciduenas, L., 2016. Magnetite pollution nanoparticles in the human brain. Proc. Natl. Acad. Sci. U. S. A. 113, 10797-10801. https://doi.org/10.1073/pnas.1605941113

Malakar, A., Snow, D.D., 2020. Nanoparticles as inorganic pollutant in water. In: Devi, P., Singh, P., Kansal, S.K. (Eds.), Inorganic Pollutants in Water. Elsevier, Oxford, UK, p. 440.

Malakar, A., Snow, D.D., Ray, C., 2019. Irrigation water quality-a contemporary perspective. Water 11, 1482. https://doi.org/10.3390/w11071482

Malakar, A., Kaiser, M., Snow, D.D., Walia, H., Panda, B., Ray, C., 2020. Ferrihydrite reduction increases arsenic and uranium bioavailability in unsaturated soil. Environ. Sci. Technol. 54 (21), 13839-13848. https://doi.org/10.1021/acs. est.0c02670

Mantecca, P., Kasemets, K., Deokar, A., Perelshtein, I., Gedanken, A., Bahk, Y.K., Kianfar, B., Wang, J., 2017. Airborne nanoparticle release and toxicological risk from metaloxide- coated textiles: toward a multiscale safe-by-design approach. Environ. Sci. Technol. 51, 9305-9317. https://doi.org/10.1021/acs.est.7b02390

Maters, E.C., Delmelle, P., Bonneville, S., 2016. Atmospheric processing of volcanic glass: effects on iron solubility and redox speciation. Environ. Sci. Technol. 50, 5033-5040. https://doi.org/10.1021/acs.est.5b06281

McClements, D.J., Xiao, H., 2017. Is nano safe in foods? Establishing the factors impacting the gastrointestinal fate and toxicity of organic and inorganic food-grade nanoparticles. npj Sci. Food 1, 6. https://doi.org/10.1038/ s41538-017-0005-1

Meermann, B., Nischwitz, V., 2018. ICP-MS for the analysis at the nanoscale - a tutorial review. J. Anal. At. Spectrom. 33, 1432-1468. https://doi.org/10.1039/ C8]A00037A

Mejia, J., Roden, E.E., Ginder-Vogel,M., 2016. Influence of oxygen and nitrate on fe (hydr) oxide mineral transformation and soil microbial communities during redox cycling. Environ. Sci. Technol. 50, 3580-3588. https://doi.org/10.1021/acs. est.5b05519 
Michalkova, H., Skubalova, Z., Sopha, H., Strmiska, V., Tesarova, B., Dostalova, S., Svec, P., Hromadko, L.,Motola,M., Macak, J.M., Adam, V., Heger, Z., 2020. Complex cytotoxicity mechanism of bundles formed from self-organised 1-D anodic TiO2 nanotubes layers. J. Hazard. Mater. 388, 122054. https://doi.org/10.1016/j. ¡hazmat.2020.122054

Miller, M.R., Raftis, J.B., Langrish, J.P., McLean, S.G., Samutrtai, P., Connell, S.P., Wilson, S., Vesey, A.T., Fokkens, P.H.B., Boere, A.J.F., Krystek, P., Campbell, C.J., Hadoke, P.W.F., Donaldson, K., Cassee, F.R., Newby, D.E., Duffin, R., Mills, N.L., 2017. Inhaled nanoparticles accumulate at sites of vascular disease. ACS Nano 11, 4542-4552. https://doi.org/10.1021/acsnano.6b08551

Moraes Moreira Carraro, T.C., Altmeyer, C., Maissar Khalil, N., Mara Mainardes, R., 2017. Assessment of in vitro antifungal efficacy and in vivo toxicity of amphotericin Bloaded PLGA and PLGA-PEG blend nanoparticles. J. Mycol. Med. 27, 519-529. https://doi.org/10.1016/j.mycmed.2017.07.004

Moreno-Martin, G., Sanz-Landaluze, J., Madrid, Y., 2017. Nanospeciation analysis using field flow fractionation. Encyclopedia of Analytical Chemistry. John Wiley \& Sons, Ltd, Chichester, UK, pp. 1-24 https://doi.org/10.1002/9780470027318. a9395

Nangia, S., Sureshkumar, R., 2012. Effects of nanoparticle charge and shape anisotropy on translocation through cell membranes. Langmuir 28, 1766617671. https://doi.org/10.1021/la303449d

Neil, C.W., Ray, J.R., Lee, B., Jun, Y.S., 2016. Fractal aggregation and disaggregation of newly formed iron(III) (hydr)oxide nanoparticles in the presence of natural organic matter and arsenic. Environ. Sci. Nano 3, 647-656. https://doi. org/10.1039/c5en00283d

Ning, H., Zhou, Y., Zhou, Z., Cheng, S., Huang, R., 2017. Challenges to improving occupational health in China. Occup. Environ. Med. 74, 924-925. https://doi. org/10.1136/oemed-2017-104656

Oberbek, P., Kozikowski, P., Czarnecka, K., Sobiech, P., Jakubiak, S., Jankowski, T., 2019. Inhalation exposure to various nanoparticles in work environmentcontextual information and results of measurements. J. Nanopart. Res. 21, 222. https://doi.org/10.1007/s11051-019-4651-x

Pavlovic, M., Adok-Sipiczki, M., Horváth, E., Szabó, T., Forró, L., Szilagyi, I., 2015. Dendrimer-stabilized titanate nanowire dispersions as potential nanocarriers. J. Phys. Chem. C 119, 24919-24926. https://doi.org/10.1021/acs.jpcc.5b08775

Peters, R.J.B., van Bemmel, G., Milani, N.B.L., den Hertog, G.C.T., Undas, A.K., van der Lee, M., Bouwmeester, H., 2018. Detection of nanoparticles in Dutch surface waters. Sci. Total Environ. 621, 210-218. https://doi.org/10.1016/j. scitotenv.2017.11.238

Pini, M., Salieri, B., Ferrari, A.M., Nowack, B., Hischier, R., 2016. Human health characterization factors of nano-TiO2 for indoor and outdoor environments. Int. J. Life Cycle Assess. 21, 1452-1462. https://doi.org/10.1007/s11367-016-1115-8

Pokhrel, L.R., Ettore, N., Jacobs, Z.L., Zarr, A., Weir, M.H., Scheuerman, P.R., Kanel, S.R., Dubey, B., 2017. Novel carbon nanotube (CNT)-based ultrasensitive sensors for trace mercury(II) detection in water: a review. Sci. Total Environ. 574, 13791388. https://doi.org/10.1016/j.scitotenv.2016.08.055 
Rahmatpour, S., Mosaddeghi, M.R., Shirvani, M., Šimůnek, J., 2018. Transport of silver nanoparticles in intact columns of calcareous soils: the role of flow conditions and soil texture. Geoderma 322, 89-100. https://doi.org/10.1016/j. geoderma.2018.02.016

Ropers,M.-H., Terrisse, H.,Mercier-Bonin,M., Humbert, B., 2017. Titaniumdioxide as food additive. Application of Titanium Dioxide. InTech https://doi.org/10.5772/ intechopen.68883

Sahu, S.C., Zheng, J., Graham, L., Chen, L., Ihrie, J., Yourick, J.J., Sprando, R.L., 2014. Comparative cytotoxicity of nanosilver in human liver HepG2 and colon Caco2 cells in culture. J. Appl. Toxicol. 34, 1155-1166. https://doi.org/10.1002/jat.2994

Sahu, S.C., Njoroge, J., Bryce, S.M., Zheng, J., Ihrie, J., 2016a. Flow cytometric evaluation of the contribution of ionic silver to genotoxic potential of nanosilver in human liver HepG2 and colon Caco2 cells. J. Appl. Toxicol. 36, 521-531. https://doi.org/10.1002/jat.3276

Sahu, S.C., Roy, S., Zheng, J., Ihrie, J., 2016b. Contribution of ionic silver to genotoxic potential of nanosilver in human liver HepG2 and colon Caco2 cells evaluated by the cytokinesis-block micronucleus assay. J. Appl. Toxicol. 36, 532-542. https:// doi.org/10.1002/jat.3279

Sajid, M., Ilyas, M., Basheer, C., Tariq, M., Daud, M., Baig, N., Shehzad, F., 2015. Impact of nanoparticles on human and environment: reviewof toxicity factors, exposures, control strategies, and future prospects. Environ. Sci. Pollut. Res. 22, 4122-4143. https://doi.org/10.1007/s11356-014-3994-1

Saleh, T.A., 2020. Trends in the sample preparation and analysis of nanomaterials as environmental contaminants. Trends Environ. Anal. Chem., e00101 https://doi. org/10.1016/j.teac.2020.e00101

Sani-Kast, N., Scheringer, M., Slomberg, D., Labille, J., Praetorius, A., Ollivier, P., Hungerbühler, K., 2015. Addressing the complexity of water chemistry in environmental fate modeling for engineered nanoparticles. Sci. Total Environ. 535, 150-159. https://doi.org/10.1016/j.scitotenv.2014.12.025

Sarma, S.J., Bhattacharya, I., Brar, S.K., Tyagi, R.D., Surampalli, R.Y., 2015. Carbon nanotubebioaccumulation and recent advances in environmental monitoring. Crit. Rev. Environ. Sci. Technol. 45, 905-938. https://doi.org/10.1080/10643389. $\underline{2014.924177}$

Sarwar, F.,Malik, R.N., Chow, C.W., Alam, K., 2018. Occupational exposure and consequent health impairments due to potential incidental nanoparticles in leather tanneries: an evidential appraisal of South Asian developing countries. Environ. Int. 117, 164-174. https://doi.org/10.1016/j.envint.2018.04.051

Schulte, P.A., Leso, V., Niang,M., Iavicoli, I., 2019. Current state of knowledge on the health effects of engineered nanomaterials in workers: a systematic review of human studies and epidemiological investigations. Scand. J. Work Environ. Health 45, 217-238. https://doi.org/10.5271/sjweh.3800

Senut, M.C., Zhang, Y., Liu, F., Sen, A., Ruden, D.M., Mao, G., 2016. Size-dependent toxicity of gold nanoparticles on human embryonic stem cells and their neural derivatives. Small 12, 631-646. https://doi.org/10.1002/smll.201502346 
Shan, X., Xu, T., Liu, Z., Hu, X., Zhang, Y.-D., Wang, B., 2017. Safety and toxicology of the intravenous administration of Ang2-siRNA plasmid chitosan magnetic nanoparticles. Mol. Med. Rep. 15, 736-742. https://doi.org/10.3892/ $\underline{\text { mmr.2016.6090 }}$

Sharma, V.K., Zboril, R., 2017. Silver nanoparticles in natural environment: formation, fate, and toxicity. In: Yan, B., Zhou, H., GardeaTorresdey, J.L. (Eds.), Bioactivity of Engineered Nanoparticles, Nanomedicine and Nanotoxicology. Springer-Verlag Singapore Pte Ltd, 152 Beach Road, \#21-01/04 Gateway East, Singapore, 189721, Singapore, pp. 239-258 https://doi.org/10.1007/978-981-10-5864-6 10

Sharma, V.K., Filip, J., Zboril, R., Varma, R.S., 2015. Natural inorganic nanoparticlesformation, fate, and toxicity in the environment. Chem. Soc. Rev. 44, 8410-8423. https://doi.org/10.1039/c5cs00236b

Shen, Y., Zhu, X., Zhu, L., Chen, B., 2017. Synergistic effects of 2D graphene oxide nanosheets and 1D carbon nanotubes in the constructed 3D carbon aerogel for high performance pollutant removal. Chem. Eng. J. 314, 336-346. https://doi. org/10.1016/j.cej.2016.11.132

Simeonidis, K., Mourdikoudis, S., Kaprara, E., Mitrakas, M., Polavarapu, L., 2016. Inorganic engineered nanoparticles in drinking water treatment: a critical review. Environ. Sci. Water Res. Technol. 2, 43-70. https://doi.org/10.1039/c5ew00152h

Singh, A.K., 2016. Engineered Nanoparticles, MRS Bulletin. Elsevier https://doi. org/10.1016/C2013-0-18974-X

Soares, A., Ramos, S., Albergaria, T., Delerue-Matos, C., 2018. Green zero valent iron nanoparticles dispersion through a sandy column using different injection sequences. Sci. Total Environ. 637-638, 935-942. https://doi.org/10.1016/j. scitotenv.2018.05.096

Sousa, V.S., Ribau Teixeira, M., 2020. Metal-based engineered nanoparticles in the drinking water treatment systems: a critical review. Sci. Total Environ. 707, 136077. https://doi.org/10.1016/j.scitotenv.2019.136077.

Srivastava, S.K., Ogino, C., Kondo, A., 2015. Nanoparticle synthesis by biogenic approach. Green Processes for Nanotechnology: From Inorganic to Bioinspired Nanomaterials. Springer International Publishing, Cham, pp. 237-257 https:// doi.org/10.1007/978-3-319-15461-9_8

Steckiewicz, K.P., Barcinska, E., Malankowska, A., Zauszkiewicz-Pawlak, A., Nowaczyk, G., Zaleska-Medynska, A., Inkielewicz-Stepniak, I., 2019. Impact of gold nanoparticles shape on their cytotoxicity against human osteoblast and osteosarcoma in in vitro model. Evaluation of the safety of use and anticancer potential. J. Mater. Sci. Mater. Med. 30, 22. https://doi.org/10.1007/ $\underline{\text { s10856-019-6221-2 }}$

Stefaniuk, M., Oleszczuk, P., Ok, Y.S., 2016. Review on nano zerovalent iron (nZVI): from synthesis to environmental applications. Chem. Eng. J. https://doi. org/10.1016/j.cej.2015.11.046

Su, S., Sun, Q., Gu, X., Xu, Y., Shen, J., Zhu, D., Chao, J., Fan, C., Wang, L., 2019. Twodimensional nanomaterials for biosensing applications. TrAC Trends Anal. Chem. 119, 115610. https://doi.org/10.1016/i.trac.2019.07.021 
Sukhanova, A., Poly, S., Shemetov, A., Nabiev, I.R., 2012. Quantum dots induce chargespecific amyloid-like fibrillation of insulin at physiological conditions. In: Choi, S.H., Choy, J.-H., Lee, U., Varadan, V.K. (Eds.), Nanosystems in Engineering and Medicine, p. 85485F https://doi.org/10.1117/12.946606

Sukhanova, A., Bozrova, S., Sokolov, P., Berestovoy, M., Karaulov, A., Nabiev, I., 2018. Dependence of nanoparticle toxicity on their physical and chemical properties. Nanoscale Res. Lett. 13, 44. https://doi.org/10.1186/s11671-018-2457-x

Sun, T.Y., Bornhöft, N.A., Hungerbühler, K., Nowack, B., 2016. Dynamic probabilistic modeling of environmental emissions of engineered nanomaterials. Environ. Sci. Technol. 50, 4701-4711. https://doi.org/10.1021/acs.est.5b05828

Sun, T.Y., Mitrano, D.M., Bornhöft, N.A., Scheringer, M., Hungerbühler, K., Nowack, B., 2017. Envisioning nano release dynamics in a changing world: using dynamic probabilistic modeling to assess future environmental emissions of engineered nanomaterials. Environ. Sci. Technol. 51, 2854-2863. https://doi.org/10.1021/ acs.est.6b05702

Sykes, E.A., Chen, J., Zheng, G., Chan,W.C.W., 2014. Investigating the impact of nanoparticle size on active and passive tumor targeting efficiency. ACS Nano 8, 5696-5706. https://doi.org/10.1021/nn500299p

Tabasum, S., Younas, M., Zaeem, M.A., Majeed, I., Majeed, M., Noreen, A., Iqbal, M.N., Zia, K.M., 2019. A review on blending of corn starch with natural and synthetic polymers, and inorganic nanoparticles with mathematical modeling. Int. J. Biol. Macromol. 122, 969-996. https://doi.org/10.1016/j.ijbiomac.2018.10.092

Taghipour, S., Hosseini, S.M., Ataie-Ashtiani, B., 2019. Engineering nanomaterials forwater and wastewater treatment: review of classifications, properties and applications. New J. Chem. 43, 7902-7927. https://doi.org/10.1039/c9nj00157c

Tan, C., Cao, X.,Wu, X.-J.,He, Q., Yang, J., Zhang, X., Chen, J., Zhao,W.,Han, S., Nam, G.H., Sindoro, M., Zhang, H., 2017. Recent advances in ultrathin two-dimensional nanomaterials. Chem. Rev. 117, 6225-6331. https://doi.org/10.1021/acs. chemrev.6b00558

Thomas, S., Harshita, B.S.P., Mishra, P., Talegaonkar, S., 2015. Ceramic nanoparticles: fabrication methods and applications in drug delivery. Curr. Pharm. Des. 21, 6165-6188. https://doi.org/10.2174/1381612821666151027153246

Troester, M., Brauch, H.J., Hofmann, T., 2016. Vulnerability of drinking water supplies to engineered nanoparticles. Water Res. 96, 255-279. https://doi.org/10.1016/j. watres.2016.03.038

Turan, N.B., Erkan, H.S., Engin, G.O., Bilgili, M.S., 2019. Nanoparticles in the aquatic environment: usage, properties, transformation and toxicity-a review. Process. Saf. Environ. Prot. 130, 238-249. https://doi.org/10.1016/j.psep.2019.08.014

Venkatesan, A.K., Rodríguez, B.T.,Marcotte, A.R., Bi, X., Schoepf, J., Ranville, J.F., Herckes, P., Westerhoff, P., 2018. Using single-particle ICP-MS for monitoring metal-containing particles in tap water. Environ. Sci. Water Res. Technol. 4, 19231932. https://doi.org/10.1039/c8ew00478a

Vindedahl, A.M., Strehlau, J.H., Arnold, W.A., Penn, R.L., 2016. Organic matter and iron oxide nanoparticles: aggregation, interactions, and reactivity. Environ. Sci. Nano 3, 494-505. https://doi.org/10.1039/c5en00215j 
Voegelin, A., Senn, A.C., Kaegi, R., Hug, S.J., 2019. Reductive dissolution of As(V)bearing Fe (III)-precipitates formed by Fe(II) oxidation in aqueous solutions. Geochem. Trans. 20, 2. https://doi.org/10.1186/s12932-019-0062-2

Wagner, S., Gondikas, A., Neubauer, E., Hofmann, T., Von Der Kammer, F., 2014. Spot the difference: engineered and natural nanoparticles in the environmentrelease, behavior, and fate. Angew. Chem. Int. Ed. 53, 12398-12419. https://doi. org/10.1002/anie.201405050

Wang, Y., 2014. Nanogeochemistry: nanostructures, emergent properties and their control on geochemical reactions and mass transfers. Chem. Geol. 378-379, 1-23. https://doi.org/10.1016/j.chemgeo.2014.04.007

Wang, Q.H., Kalantar-Zadeh, K., Kis, A., Coleman, J.N., Strano, M.S., 2012. Electronics and optoelectronics of two-dimensional transition metal dichalcogenides. Nat. Nanotechnol. https://doi.org/10.1038/nnano.2012.193

Wang, B., Zhou, X., Chai, Z., Zhao, Y., Feng, W., Yin, J.-J., Kurash, I., 2013. Physicochemical origin for free radical generation of iron oxide nanoparticles in biomicroenvironment: catalytic activities mediated by surface chemical states. J. Phys. Chem. C 117, 383-392. https://doi.org/10.1021/ip3101392

Wang, L., Yan, L., Liu, J., Chen, C., Zhao, Y., 2018. Quantification of nanomaterial/ nanomedicine trafficking in vivo. Anal. Chem. 90, 589-614. https://doi. org/10.1021/acs.analchem.7b04765

Wang, J., Nabi, M.M., Mohanty, S.K., Afrooz, A.N., Cantando, E., Aich, N., Baalousha, M., 2020. Detection and quantification of engineered particles in urban runoff. Chemosphere 248, 126070. https://doi.org/10.1016/j. chemosphere.2020.126070

Wei, W., Zhang, X., Zhang, S., Wei, G., Su, Z., 2019. Biomedical and bioactive engineered nanomaterials for targeted tumor photothermal therapy: a review. Mater. Sci. Eng. C 104, 109891. https://doi.org/10.1016/j.msec.2019.109891

Westerhoff, P., Atkinson, A., Fortner, J., Wong, M.S., Zimmerman, J., Gardea-Torresdey, J., Ranville, J., Herckes, P., 2018. Low risk posed by engineered and incidental nanoparticles in drinking water. Nat. Nanotechnol. 13, 661-669. https://doi. org/10.1038/s41565-018-0217-9

Westmeier, D., Solouk-Saran, D., Vallet, C., Siemer, S., Docter, D., Götz, H., Männ, L., Hasenberg, A., Hahlbrock, A., Erler, K., Reinhardt, C., Schilling, O., Becker, S., Gunzer, M., Hasenberg, M., Knauer, S.K., Stauber, R.H., 2018. Nanoparticle decoration impacts airborne fungal pathobiology. Proc. Natl. Acad. Sci. 115, 70877092. https://doi.org/10.1073/pnas.1804542115

Wille, G., Hellal, J., Ollivier, P., Richard, A., Burel, A., Jolly, L., Crampon, M., Michel, C., 2017. Cryo-Scanning Electron Microscopy (SEM) and Scanning Transmission Electron Microscopy (STEM)-in-SEM for bio- and organo-mineral interface characterization in the environment. Microsc. Microanal. 23, 1159-1172. https:// doi.org/10.1017/S143192761701265X

Winkler, H.C., Suter, M., Naegeli, H., 2016. Critical review of the safety assessment of nano-structured silica additives in food. J. Nanobiotechnol. 14, 44. https://doi. org/10.1186/s12951-016-0189-6 
Winkler, H.C., Notter, T., Meyer, U., Naegeli, H., 2018. Critical review of the safety assessment of titanium dioxide additives in food. J. Nanobiotechnol. 16, 51. https://doi.org/10.1186/s12951-018-0376-8

Xiao, T., Huang, J., Wang, D., Meng, T., Yang, X., 2020. Au and Au-based nanomaterials: synthesis and recent progress in electrochemical sensor applications. Talanta 206, 120210. https://doi.org/10.1016/j.talanta.2019.120210

Xu, Z., Lu, J., Zheng, X., Chen, B., Luo, Y., Tahir, M.N., Huang, B., Xia, X., Pan, X., 2020. A critical review on the applications and potential risks of emerging MoS2 nanomaterials. J. Hazard. Mater. 399, 123057. https://doi.org/10.1016/j. jhazmat.2020.123057

Xue,W., Huang, D., Zeng, G.,Wan, J., Cheng, M., Zhang, C., Hu, C., Li, J., 2018. Performance and toxicity assessment of nanoscale zero valent iron particles in the remediation of contaminated soil: a review. Chemosphere 210, 1145-1156. https://doi.org/10.1016/j.chemosphere.2018.07.118

Yecheskel, Y., Dror, I., Berkowitz, B., 2016. Transport of engineered nanoparticles in partially saturated sand columns. J. Hazard. Mater. 311, 254-262. https://doi. org/10.1016/i.jhazmat.2016.03.027

Yin, Y., Yu, S., Liu, J., Jiang, G., 2014. Thermal and photoinduced reduction of ionic $\mathrm{Au}(\mathrm{III})$ to elemental $\mathrm{Au}$ nanoparticles by dissolved organic matter in water: possible source of naturally occurring Au nanoparticles. Environ. Sci. Technol. 48, 2671-2679. https://doi.org/10.1021/es404195r

Zhang, Z., Yang, X., Shen, M., Yin, Y., Liu, J., 2015. Sunlight-driven reduction of silver ion to silver nanoparticle by organic matter mitigates the acute toxicity of silver to Daphnia magna. J. Environ. Sci. 35, 62-68. https://doi.org/10.1016/j. jes.2015.03.007

Zhang, W., Xiao, B., Fang, T., 2018. Chemical transformation of silver nanoparticles in aquatic environments: mechanism, morphology and toxicity. Chemosphere 191, 324-334. https://doi.org/10.1016/j.chemosphere.2017.10.016

Zou, Y., Wang, Xiangxue, Khan, A., Wang, P., Liu, Y., Alsaedi, A., Hayat, T., Wang, Xiangke, 2016. Environmental remediation and application of nanoscale zerovalent iron and its composites for the removal of heavy metal ions: a review. Environ. Sci. Technol. 50, 7290-7304. https://doi.org/10.1021/acs.est.6b01897 